\title{
Phosphate Transporter Regulator That Prevents Abnormal Hyperphosphatemia.
}

\section{Sumire Sasaki}

Tokushima University Graduate School

\section{Yuji Shiozaki}

Tokushima University Graduate School

Ai Hanazaki

Tokushima University Graduate School

Megumi Koike

Tokushima University Graduate School

Kazuya Tanifuji

Tokushima University Graduate School

Minori Uga

Tokushima University Graduate School

Kota Kawahara

Tokushima University Graduate School

Ichiro Kaneko

Tokushima University Graduate School

Yasuharu Kawamoto

Osaka University

Pattama Wiriyasermkul

The Jikei University School of Medicine

Tomoka Hasegawa

Hokkaido University Faculty of Dental Medicine

Norio Amizuka

Hokkaido University Faculty of Dental Medicine

Ken-ichi Miyamoto

Tokushima University Graduate School

Shushi Nagamori

The Jikei University School of Medicine

Yoshikatsu Kanai

Osaka University

Hiroko Segawa ( $\nabla$ segawa@tokushima-u.ac.jp )

Tokushima University Graduate School 


\section{Research Article}

Keywords: phosphate, concentration, increase, hormone

Posted Date: December 17th, 2021

DOI: https://doi.org/10.21203/rs.3.rs-1129985/v1

License: (c) (i) This work is licensed under a Creative Commons Attribution 4.0 International License. Read Full License 
$12 / 13 / 21$

1 Phosphate transporter regulator that prevents abnormal hyperphosphatemia.

2

3

4 Sumire Sasaki ${ }^{1}$, Yuji Shiozaki ${ }^{1}$, Ai Hanazaki ${ }^{1}$, Megumi Koike ${ }^{1}$, Kazuya Tanifuji ${ }^{1}$, Minori Uga ${ }^{1}$,

5 Kota Kawahara ${ }^{1}$, Ichiro Kaneko ${ }^{1}$, Yasuharu Kawamoto ${ }^{2}$, Pattama Wiriyasermkul ${ }^{3}$, Tomoka

6 Hasegawa $^{4}$, Norio Amizuka ${ }^{4}$, Ken-ichi Miyamoto ${ }^{1,5}$, Shushi Nagamori ${ }^{3 *}$, Yoshikatsu Kanai ${ }^{2 *}$,

$7 \quad$ Hiroko Segawa ${ }^{1 *}$

8

9

$10{ }^{1}$ Department of Applied Nutrition, Institute of Biomedical Sciences, Tokushima University

11 Graduate School, Tokushima, Japan

$12{ }^{2}$ Department of Bio-system Pharmacology, Graduate School of Medicine, Osaka University,

13 Osaka, Japan

$14{ }^{3}$ Department of Laboratory Medicine, The Jikei University School of Medicine, Tokyo, Japan

$15{ }^{4}$ Developmental Biology of Hard Tissue, Hokkaido University Faculty of Dental Medicine,

16 Sapporo, Japan

$17{ }^{5}$ Graduate School of Agriculture, Ryukoku University, Ohtsu, Japan

18

19 Short Title: TRAP is a novel regulator of Pi metabolism

20

21

22

23 
Abstract

Renal type II sodium-dependent inorganic phosphate (Pi) transporters NaPi2a and NaPi2c cooperate with other organs to strictly regulate the plasma Pi concentration. A high Pi load induces the phosphaturic hormones parathyroid hormone (PTH) and fibroblast growth factor 23 (FGF23), enhances urinary Pi excretion and prevents the onset of hyperphosphatemia. How FGF23 is induced from the bones by a high Pi load and the setpoint of the plasma Pi concentration, however, are unclear. Here, we investigated the role of transporter-associated protein (TRAP), found in gene co-expression networks in NaPi2a and $\mathrm{NaPi} 2 \mathrm{c}$ function. TRAP is localized in the renal proximal tubules and interacts with NaPi2a. In TRAP-knockout (KO) mice, the serum FGF23 concentration was markedly increased but increased Pi excretion and hypophosphatemia were not observed. In addition, TRAP-KO mice exhibit reduced NaPi2a responsiveness to FGF23 and PTH administration. Furthermore, a dietary Pi load causes marked hyperphosphatemia and abnormal NaPi2a regulation in TRAP-KO mice. Thus, TRAP is thought to be associated with FGF23 induction in bones and the regulation of NaPi2a to prevent an increase in the plasma Pi concentration due to a high Pi load and kidney injury. 
Introduction

$\mathrm{NaPi} 2 \mathrm{a}$ and $\mathrm{NaPi2c}$ (SLC34A1/NPT2A/NaPi2a and SCL34A3/NPT2C/NaPi2c), sodiumdependent phosphate transporters responsible for inorganic phosphate $(\mathrm{Pi})$ reabsorption in the kidney, are essential molecules for regulating the plasma Pi concentration. Both transporters are predominantly expressed at the apical side in the proximal tubules of the kidney ${ }^{1,2}$. Parathyroid hormone (PTH) and fibroblast growth factor 23 (FGF23) are the main contributing hormones regulating the renal NaPi2a and NaPi2c transporters ${ }^{1-5}$. In rodents, NaPi2a plays a central role in Pi reabsorption ${ }^{6,7}$. NaPi2a has a PDZ (PSD-95, Disc-large, ZO-1)-binding motif at its C-terminus and binds to $\mathrm{Na}^{+} / \mathrm{H}^{+}$exchanger regulatory factor (NHERF) 1 to form a complex at the apical membrane of proximal tubular cells ${ }^{8-10}$. PTH and FGF23 phosphorylate NHERF1, thereby dissociating the complex, and NaPi2a is endocytosed and degraded in lysosomes ${ }^{1,11-13}$. In this way, phosphaturic hormones reduce NaPi2a and enhance urinary Pi excretion.

Dietary Pi intake regulates urinary Pi excretion by altering plasma PTH and FGF23 levels 5 . Both phosphaturic hormones affect $\mathrm{NaPi} 2 \mathrm{a}$ and $\mathrm{NaPi} 2 \mathrm{c}$ expression in the proximal tubular cells $\mathrm{s}^{1}$ 2, 5 . With a low Pi diet intake, plasma PTH and FGF23 levels decrease, and the NaPi2a/NaPi2c levels in the proximal tubular cells increase. Therefore, urinary Pi excretion is reduced. In contrast, with a high dietary Pi load, plasma PTH and FGF23 levels are increased to promote the internalization of $\mathrm{NaPi} 2 \mathrm{a}$ and $\mathrm{NaPi} 2 \mathrm{c}$ in the proximal tubular cells. As a result, urinary $\mathrm{Pi}$ excretion is enhanced, and the onset of hyperphosphatemia is prevented. The mechanisms underlying both the induction of phosphaturic hormones by dietary Pi and regulation of the serum Pi concentration, however, remain unclear.

Gene co-expression networks (GCNs) represent gene-gene interactions and while they do not contain information about regulation direction, they allow for the simultaneous analysis of many genes and their potential relationships with each other ${ }^{14-17}$. In the present study, we 
focused on transmembrane protein (TMEM)174, which is strongly correlated with slc34a1 in the GCNs. TMEM174 (a transporter associated protein; TRAP) is localized in the renal proximal tubule apical membrane. The present study showed that TRAP-knockout (KO) mice exhibit abnormal fluctuations in the plasma Pi levels in response to dietary Pi. TRAP binds to NaPi2a on the cell membrane and is considered to be involved in the regulation of NaPi2a by PTH and FGF23. The roles of TRAP in the control of plasma Pi are discussed.

\section{Results}

COXPRESdb search indicates co-expression of transmembrane protein 174 (TMEM174) with renal NaPi transporters. To identify genes co-regulated with slc34a1 or slc34a3 mouse $\mathrm{NaPi}$ transporters, we searched for genes using the COXPRESdb $v 7^{16}$. The top 20 genes are listed in Supplemental Table S1 and S2, and the transmembrane protein 174 (TMEM174) gene was identified as a significant gene co-expressed with slc34a1 and slc34A3. The correlation coefficient (r) for gene expression levels between slc34a1 or slc34a3 and TMEM174 was 0.899717818157933 and 0.36902441214734 , respectively (Fig. 1a, 1b).

TMEM174 was originally identified among a large pool of genes by high-throughput cell screening technology to isolate functional genes and provide insight into the mechanisms of gene function $^{18-20}$. The full-length amino acid sequences of TMEM174 in mouse (NP_080961.1), rat (NP_001019469.1), and human (NP_694949.1) are reported in the NCBI database. The putative TMEM174 protein comprises 243 amino acids with 2 transmembrane domains. In the present study, we named TMEM174 as a transporter-associated protein (TRAP).

Tissue localization of TRAP expression and possible involvement in Pi homeostasis. Expression of TRAP mRNA was analyzed by real-time polymerase chain reaction (PCR) using 
mouse tissues. As reported in human tissue ${ }^{18}$, mouse TRAP mRNA was markedly higher in the kidney compared with other tissues (Fig. 2a). TRAP protein expression was detected at the apical membrane of renal proximal tubular cells, but not in the distal tubule (Fig. 2b). Next, we examined whether the renal TRAP protein expression was regulated by dietary Pi regulation and deletion of renal Pi transporters NaPi2a, or NaPi2c (Fig. 2c-2e). A low Pi (LP) diet significantly induced renal TRAP protein expression compared with control Pi (CP) and high Pi (HP) diets, similar to the response of renal Pi transporters to dietary Pi content (Fig. 2c and 2d). Furthermore, deletion of renal NaPi transporters (NaPi2a-KO and NaPi2c-KO mice) significantly reduced the renal TRAP protein expression levels compared with $\mathrm{NaPi} 2 \mathrm{a}^{+/+} \mathrm{NaPi} 2 \mathrm{c}^{+/+}$mice (Fig. 2e).

Characterization of TRAP ${ }^{-/-}$mice fed standard mouse chow. To generate TRAP-null mice, we replaced TRAP exon 1 to part of exon 2 with a neomycin-resistant gene (Supplemental Fig. S1a). We confirmed the mutant genomic DNA isolated from transfected ES clones by Southern blotting, and the mice genotype by PCR analysis (Supplemental Fig. S1b, S1c). Reverse transcriptase-PCR with TRAP-specific primers and Western blotting analysis confirmed the absence of detectable renal TRAP mRNA and protein expression in TRAP $^{-/-}$mice (Fig. 3a, 3b). Male and female TRAP $^{-}$ ${ }^{\text {/. }}$ mice showed similar weight gain compared with $\mathrm{TRAP}^{+/+}$and $\mathrm{TRAP}^{+/-}$mice (Fig. 3c). Between 4 to 5 weeks of age, however, male $\mathrm{TRAP}^{-/}$mice showed significantly lower body weight than male TRAP $^{+/+}$and TRAP $^{+-}$mice (Fig. 3c left). To measure food intake, and urine and fecal biochemical data, mice were individually placed in metabolic cages. TRAP ${ }^{-/-}$mice did not show a significant difference in food intake, plasma creatinine, plasma blood urea nitrogen (BUN), blood ionized $\mathrm{Ca}$ and plasma Pi concentrations, fecal and urinary $\mathrm{Ca}$, Pi excretion levels, or other blood biochemistry parameters compared with $\mathrm{TRAP}^{+/+}$and $\mathrm{TRAP}^{-/-}$mice (Fig. 3d-1, and Supplemental Table S3). 
Trends in Pi-regulating hormones in TRAP $^{-/-}$mice. Plasma $1,25(\mathrm{OH})_{2} \mathrm{D}_{3}$ levels were not significantly different among the 3 groups (Fig. 4a). Plasma PTH, and especially serum intact FGF23 levels were markedly higher in $\mathrm{TRAP}^{-/}$mice than in $\mathrm{TRAP}^{+/+}$and $\mathrm{TRAP}^{+/-}$mice (Fig. 4b, 4c). Renal 25-hydroxyvitamin D-1 alpha hydroxylase (Cyp27b1) mRNA levels were not significantly different among the 3 groups, but renal 25-hydroxyvitamin D-24-hydroxylase (Cyp24a1) mRNA levels were significantly higher in $\mathrm{TRAP}^{-/ /}$mice than in $\mathrm{TRAP}^{+/+}$and TRAP $^{+/-}$mice (Fig. 4d, 4e). Parathyroid PTH mRNA levels were not significantly different among the 3 groups (Fig. 4f). FGF23 mRNA was mainly detected in osseous-tissues but has been found in other tissues as well ${ }^{21}$. Expression of FGF23 mRNA in the bone was highly increased in $\mathrm{TRAP}^{-/}$mice compared with $\mathrm{TRAP}^{+/+}$mice, and to a lower extent in the spleen and thymus, but not in the heart (Fig. 4g). In both $\mathrm{TRAP}^{+/+}$and $\mathrm{TRAP}^{-/-}$mice, FGF23 immunostaining was observed in osteocytes and osteoblasts/preosteoblasts, with no difference in the localization patterns. The number of FGF23-positive cells, however, tended to be increased in $\mathrm{TRAP}^{-/-}$mice (Fig. 4h).

Bone histochemical analysis in TRAP $^{--}$mice. Bone analysis was performed in young (8week-old) and aged (70-week-old) mice (Supplemental Fig. S2 and Fig. 5). Compared with

140 the micro-computed tomography (CT) analysis and morphological measurement using the long bones (Supplemental Fig. S2). mice had slightly more cancellous bone at the metaphysis, and the trabeculae appeared to be

144 slightly thicker and rounded compared with those from $\mathrm{TRAP}^{+/+}$mice (Fig. 5a). In addition, 
alkaline phosphatase (ALP)/tartrate-resistant acid phosphatase staining revealed the tendency toward a thicker ALP-positive osteoblast/preosteoblast layer on the trabecular surface in TRAP ${ }^{-/-}$ mice, and a similar number of tartrate-resistant acid phosphatase-positive osteoclasts as in $\mathrm{TRAP}^{+/+}$and $\mathrm{TRAP}^{-/-}$mice, or a slightly higher number than in $\mathrm{TRAP}^{-/}$mice (Fig. 5b). Furthermore, the bone mineralization and osteoid layer thickness did not differ significantly between $\mathrm{TRAP}^{+/+}$and $\mathrm{TRAP}^{-/ /}$mice, whereas mature osteoblasts covered on the bone surface in TRAP $^{-/-}$mice (Fig. 5c).

Renal NaPi transporter expression in TRAP $^{-/-}$mice. Immunoblotting analysis using brush border membrane vesicles (BBMVs) and immunofluorescence staining showed the disappearance of only renal NaPi2c protein expression in $\mathrm{TRAP}^{-/-}$mice compared with $\mathrm{TRAP}^{+/+}$mice (Fig. 6a, 6b). In contrast, however, NaPi2a protein expression was not different between $\mathrm{TRAP}^{+/+}$or TRAP ${ }^{-}$ ${ }^{1-}$ mice (Fig. 6a, 6b). Real time-PCR showed significantly decreased slc34a1 and slc34a3 mRNA levels in $\mathrm{TRAP}^{-/}$mice compared with $\mathrm{TRAP}^{+/+}$mice (Supplemental Fig. S3a, S3b).

160 The levels of renal FGF receptor 1 (FGFR1) and PTH receptor (PTHR) mRNA were the same 161 between $\mathrm{TRAP}^{+/+}$and $\mathrm{TRAP}^{-/-}$mice, and renal FGFR4 and $\alpha-\mathrm{Klotho}$ mRNA levels were 162 significantly decreased in $\mathrm{TRAP}^{-/}$mice compared with TRAP ${ }^{+/+}$mice (Supplemental Fig. S3cS3f). FGFR1 protein expression was not different between $\mathrm{TRAP}^{+/+}$and $\mathrm{TRAP}^{-/-}$mice, and $\alpha-$ Klotho protein expression was significantly decreased in $\mathrm{TRAP}^{-/-}$mice compared with $\mathrm{TRAP}^{+/+}$ mice (Fig. 6c). Phosphorylation of the extracellular signal-regulated kinase (ERK)1/2 also was not different between TRAP $^{+/+}$and TRAP $^{-/}$mice (Fig. 6d). 
the apical membrane is dependent on its association with PDZ-containing proteins , 8, 9, 22-24 $^{\text {PTH }}$ and FGF23 regulate Pi excretion by controlling the NaPi2a/NHERF1 association ${ }^{1,10}$. Immunoblot analysis using renal BBMVs, but not whole homogenate, showed that NHERF1 protein expression was significantly higher in $\mathrm{TRAP}^{-/-}$mice than in $\mathrm{TRAP}^{+/+}$mice (Fig. 7a, 7b). BBMVs of wild-type (WT), TRAP-KO, and NaPi2a-KO mice (Fig. 7c, 7d). NHERF1 immunoprecipitation analysis revealed a NaPi2a/NHERF1 interaction in both WT and TRAP-KO mice. In contrast, NHERF1 immunoprecipitation analysis detected TRAP protein in WT mice, but not in NaPi2a-KO mice (Fig. 7c). These findings suggest that TRAP binds to NHERF1 in the presence of NaPi2a but cannot interact in the absence of NaPi2a. TRAP immunoprecipitation analyses showed a direct interaction between TRAP and NaPi2a (Fig. 7d).

Response to the dietary Pi content in TRAP KO mice. We examined fluctuations in the plasma Pi levels due to differences in the dietary Pi content (Fig. 8a). TRAP ${ }^{-/-}$mice fed the HP diet had markedly higher plasma Pi levels than $\mathrm{TRAP}^{+/+}$mice. Furthermore, $\mathrm{TRAP}^{-/-}$mice fed the $\mathrm{CP}$ or HP diets had extremely high serum FGF23 levels compared with TRAP $^{+/+}$mice fed an equivalent diet (Fig. 8b). In addition, renal NaPi2a, but not $\mathrm{NaPi} 2 \mathrm{c}$, protein expression levels were significantly higher in $\mathrm{TRAP}^{-/}$mice fed the LP, CP, or HP diet compared with $\mathrm{TRAP}^{+/+}$mice fed the same diet (Fig. 8c). In contrast, the CP diet and HP diet significantly suppressed renal NaPi2c protein expression levels in $\mathrm{TRAP}^{-/-}$mice compared with $\mathrm{TRAP}^{+/+}$mice (Fig. 8c). NaPi2a immunofluorescence staining was strongly detected at the apical membrane of proximal tubular cells both in $\mathrm{TRAP}^{+/+}$and TRAP ${ }^{-/-}$mice fed the LP diet (Fig. 8d). The HP diet suppressed NaPi2a staining at the apical membrane in $\mathrm{TRAP}^{+/+}$mice. In contrast, $\mathrm{TRAP}^{-/-}$mice fed the HP diet 
(Fig. 8d).

Response to FGF23 in TRAP KO mice. Next, to confirm the effect of the phosphaturic action of FGF23 in TRAP ${ }^{-/}$mice, mice were fed the LP diet to reduce endogenous FGF23. Exogenous FGF23 was expressed using the Naked-DNA method, as described previously ${ }^{25-27}$. As shown in Supplemental Figure S4a, the LP diet significantly suppressed serum FGF23 levels in both $\mathrm{TRAP}^{+/+}$and $\mathrm{TRAP}^{-/ /}$mice. We confirmed the exogenous FGF23 mRNA (hFGF23) expression in the liver of the FGF23 groups in both $\mathrm{TRAP}^{+/+}$and $\mathrm{TRAP}^{-/}$mice at 4 days after Naked-DNA injection (Supplemental Fig. S4b) ${ }^{25-27}$. In $\mathrm{TRAP}^{+/+}$mice, but not in $\mathrm{TRAP}^{-/-}$mice, FGF23 increased the level of ERK1/2phosphorylation compared with the control group (Fig. 9a). Interestingly, the ERK phosphorylation level was higher in the control $\mathrm{TRAP}^{-/-}$mice compared with the control $\mathrm{TRAP}^{+/+}$mice. FGF23 groups of both $\mathrm{TRAP}^{+/+}$and $\mathrm{TRAP}^{-/-}$mice showed significantly lower levels of renal $\alpha$-Klotho protein expression compared with their control groups (Supplemental Fig. S4c). Renal Cyp27b1 mRNA levels were significantly suppressed, and Cyp24a1 mRNA levels were significantly increased in the FGF23 groups of both TRAP TH+ $^{+/}$ and $\mathrm{TRAP}^{-/-}$mice compared with their control groups (Supplemental Fig. S4d, S4e). Slc34a1, but not slc34a3, mRNA levels were significantly suppressed in FGF23 groups of both TRAP ${ }^{+/+}$ and $\mathrm{TRAP}^{-/}$mice compared with the control group (Supplemental Fig. S4f, S4g). Urinary Pi excretion levels were slightly but significantly increased in FGF23 groups of both $\mathrm{TRAP}^{+/+}$and $\mathrm{TRAP}^{-/-}$mice compared with the control group (Fig. 9b). In $\mathrm{TRAP}^{+/+}$mice, both renal NaPi2a and NaPi2c protein levels were significantly suppressed after FGF23 Naked DNA injection compared with the control group (Fig. 9c). In TRAP ${ }^{-/}$mice, FGF23 significantly suppressed only $\mathrm{NaPi} 2 \mathrm{c}$ protein expression and not $\mathrm{NaPi} 2 \mathrm{a}$ protein expression levels (Fig. 9c). 
217 Response to PTH in TRAP KO mice. Next, we investigated the effect of PTH on NaPi2a protein 218 expression in $\mathrm{TRAP}^{+/+}$and $\mathrm{TRAP}^{-/-}$mice. The LP diet significantly suppressed plasma PTH levels 219 in $\mathrm{TRAP}^{+/+}$and $\mathrm{TRAP}^{-/}$mice, and the plasma PTH levels did not differ significantly between 220 TRAP $^{+/+}$and TRAP ${ }^{-/}$mice fed the LP diet (Supplemental Fig. S4h). To confirm that there was no 221 difference in PTH signaling, we measured the renal cAMP level 15 min after administration of 222 PTH. PTH induced cAMP in the kidney of $\mathrm{TRAP}^{+/+}$mice, but not in $\mathrm{TRAP}^{-/-}$mice (Fig. 9d). Like 223 FGF23, renal cAMP levels were slightly, but significantly higher in the control TRAP $^{-/-}$mice than 224 in the control $\mathrm{TRAP}^{+/+}$mice. Urinary Ca excretion was significantly increased $1 \mathrm{~h}$ after PTH 225 administration in both $\mathrm{TRAP}^{+/+}$and $\mathrm{TRAP}^{-/-}$mice (Fig. 9e). Urinary Pi excretion, however, was significantly increased $1 \mathrm{~h}$ after $\mathrm{PTH}$ administration in $\mathrm{TRAP}^{+/+}$mice, but not in $\mathrm{TRAP}^{-/-}$mice (Fig. 9f). Furthermore, PTH significantly suppressed renal NaPi2a protein expression in TRAP ${ }^{+/+}$ mice, but not in $\mathrm{TRAP}^{-/}$mice (Fig 9g). We confirmed NaPi2a internalization in the kidney of $\mathrm{TRAP}^{+/+}$mice administered PTH at $15 \mathrm{~min}$ and $1 \mathrm{~h}$, as described previously (Fig. 9h, upper $)^{28}$. In $\mathrm{TRAP}^{-/}$mice, NaPi2a remained localized at the apical membrane after administration of PTH (Fig. 9h, bottom).

Renal injury in TRAP KO mice. Finally, we investigated the plasma Pi and BUN concentrations in a folic acid (FA)-induced acute kidney injury (AKI) model for 7 days. As shown in Fig. 10a, the deletion of TRAP shortened the lifespan of the AKI model mice. There were no significant differences in BUN levels at $24 \mathrm{~h}$ and 7 days after administration of FA between $\mathrm{TRAP}^{+/+}$and TRAP $^{-/-}$mice (Fig. 10b, 10c). AKI-TRAP ${ }^{-/}$mice, however, had significantly higher levels of plasma Pi at $24 \mathrm{~h}$ after $\mathrm{FA}$ administration compared with $\mathrm{AKI}^{-\mathrm{TRAP}^{+/+}}$mice, and the hyperphosphatemia was maintained only in $\mathrm{TRAP}^{-/}$mice until 7 days after FA treatment (Fig. 10d, 10e). Furthermore, serum intact FGF23 levels were markedly higher in $\mathrm{TRAP}^{-/-}$mice at 24 
$\mathrm{h}$ after FA treatment compared with $\mathrm{TRAP}^{+/+}$mice, and the markedly high levels of serum FGF23 were maintained only in TRAP $^{-/}$mice until 7 days after FA treatment (Fig. 10f, 10g). Renal $\mathrm{NaPi}$ a protein levels were significantly reduced in $\mathrm{TRAP}^{+/+}$mice by $\mathrm{FA}$ administration, but only slightly reduced in $\mathrm{TRAP}^{-/-}$mice (Fig. 10h).

\section{Discussion}

In the present study, we investigated the roles of a strongly correlated molecule (TRAP) in the GCNs and Pi metabolism. The TRAP protein was extremely highly expressed in the kidney and localized at the apical membrane of the renal proximal tubules. Dietary Pi content regulates the renal TRAP protein levels the same as NaPi2a. Immunoprecipitation experiments suggest that TRAP interacts with the NaPi2a/NHERF1 complex (directly with NaPi2a, but not with NHERF1). $\mathrm{TRAP}^{-/-}$mice showed markedly increased serum FGF23 levels and significantly increased plasma PTH levels. Interestingly, renal NaPi2a protein levels were not decreased despite the marked increase in serum FGF23 levels. Based on studies of dietary Pi responses, the marked increase in plasma Pi levels in $\mathrm{TRAP}^{-/-}$mice are due to high Pi loading and may result from a resistance to NaPi2a regulation by PTH and FGF23. Thus, an abnormal dietary Pi response in $\mathrm{TRAP}^{-/-}$mice leads to dysregulation of plasma Pi levels.

$\mathrm{TRAP}^{-/-}$mice are characterized by 1) abnormally high serum FGF23 levels and 2) dietary Pi response abnormalities in the regulation of the plasma Pi concentration. The present findings suggest that TRAP binds to NaPi2a on the cell membrane and is involved in the internalization of NaPi2a. In TRAP ${ }^{-/}$mice, no decrease in NaPi2a was observed despite high FGF23 and PTH concentrations. On the other hand, NaPi2c was significantly decreased. In addition, NHERF1 was significantly elevated in $\mathrm{TRAP}^{-/}$mice. For these reasons, TRAP is considered to be a component of the NaPi2a/NHERF1 complex that receives signals from PTH and FGF23. 
Although TRAP deficiency affects the NaPi2a/NHERF1 system, vitamin D-metabolizing enzymes and NaPi2c regulation are considered normal. PTH and FGF23 downregulate the NaPi2a/NHERF1 binary complex by activating 2 distinct signaling pathways that converge at NHERF ${ }^{1}$. The internalization and degradation of NaPi2a increase Pi excretion and depend on activation of the ERK1/2 and serum/glucocorticoid- regulated kinase-1 pathways, resulting in phosphorylation of NHERF $1^{29}$. PTH signals activate protein kinases $A$ and $C^{13,30,31}$. Triggered by phosphorylation of NHERF1, NaPi2a dissociates from NHERF1 and is then internalized ${ }^{13}$. Not all signals from the receptor have been examined in detail, but some signals were activated. Considering the changes in NaPi2c and vitamin D-metabolizing enzymes (cyp24a1, cyp27b1) in $\mathrm{TRAP}^{-/}$mice and the effects of PTH/FGF23 administration, it is expected that they are functioning normally except for the signal to NaPi2a. The interaction of NaPi2c with NHERF3 (PDZK1) is more important than that with NHERF ${ }^{32,33}$. In fact, NaPi2c expression is suppressed in NHERF3-KO mice ${ }^{33}$. We previously reported differences in signals between the phosphaturic action of FGF23 and the inhibitory effect on vitamin D synthesis ${ }^{34}$. Therefore, it is considered that the effect of TRAP deficiency is limited to the control function of NaPi2a. More detailed studies on the role of TRAP in NaPi2a regulation, such as the effect of NHERF1 on phosphorylation, are needed. FGF23 levels cause the pathology observed in a mouse model of X-linked hypophosphatemia rickets (Hyp mice) $)^{35,36}$. On the other hand, $\mathrm{TRAP}^{-/-}$mice did not exhibit the abnormal bone morphology seen in Hyp mice and we speculate that this is because $\mathrm{TRAP}^{-/-}$mice do not develop hypophosphatemia. The bone analysis data suggest that a high PTH concentration affects clarify the role of TRAP in bone. 

is expected to signal dietary Pi levels to bone FGF23. On the other hand, in an FA-induced renal disorder model, a further increase in serum FGF23 concentration was observed in $\mathrm{TRAP}^{-/}$mice. FGF23 induction is known to be independent of dietary Pi signals in an FA-acute kidney injury model $^{37}$. Therefore, the increase in FGF23 in $\mathrm{TRAP}^{-/-}$mice may be independent of the signal of renal damage.

The relationship between $\alpha$-Klotho and TRAP as a mediator from the kidney remains unclear. $\alpha$-Klotho plays an important role in phosphate regulation by FGF23 as a co-receptor for FGFR1 in the kidney ${ }^{38,}{ }^{39}$. In $\mathrm{TRAP}^{-/-}$mice, renal $\alpha$-Klotho levels are reduced by approximately $50 \%$. Previous studies reported that a decrease in $\alpha$-Klotho in the kidney triggers the induction of FGF23 from the bone ${ }^{38,39}$. Pi retention, progressive hyperphosphatemia, rising FGF23 levels, and low $\alpha$-Klotho expression are all observed in patients with progressive chronic kidney disease $\mathrm{e}^{40-42}$. The cause of the decrease in $\alpha-\mathrm{Kl}_{\text {otho }}$ in the TRAP ${ }^{-/-}$mice kidney may be the high concentration of serum FGF23. We reported that renal $\alpha$-Klotho levels are significantly reduced in NaPi2a/NaPi2c double-KO mice, but no increase in plasma FGF23 is observed ${ }^{27}$. The reason for the increase in FGF23 in $\mathrm{TRAP}^{-/-}$mice cannot be explained by the decrease in $\alpha$-Klotho alone. A low-Pi diet suppresses the induction of FGF23 from the bone in $\alpha-\mathrm{Kl}$ otho-KO mice as well, however, suggesting that it is mediated by the same signal ${ }^{43,44}$. The relationship between TRAP and $\alpha$-Klotho in the kidney was not investigated in the present study. Finally, phosphaturic hormone is secreted in response to an excessive Pi load and acts on the kidneys to promote Pi excretion. The NaPi2a/NHERF1 complex has an important role. TRAP is expected to regulate the amount of $\mathrm{NaPi} 2 \mathrm{a}$ in response to a Pi deficiency or excess and regulates

311 the responsiveness of phosphaturic hormone. For example, vitamin D treatment in Hyp mice restores serum Pi levels by causing FGF23 resistance to NaPi2a/NHERF1 ${ }^{34,45}$. Thus, TRAP, a 
strongly correlated molecule with NaPi2a in the GCNs, is thought to be involved in the regulation of NaPi2a by phosphaturic hormones in the kidney and the prevention of hyperphosphatemia in response to a high dietary Pi load (Figure 11).

\section{Materials and Methods}

\section{Experimental animals}

319 All experimental procedures involving animals were conducted in accordance with the Tokushima University School of Medicine and Osaka University Graduate School of Medicine guidelines. This study was also carried out in compliance with the ARRIVE guidelines. All procedures involving the use of animals were subjected to approval from Tokushima University School of Medicine (T2019-126) and Osaka University Graduate School of Medicine (19-064-02) ethics committee.

Male and female C57B6/J mice were purchased from Charles River Laboratories Japan (Yokohama, Japan). NaPi2a-KO and NaPi2c-KO mice were maintained as described previously ${ }^{7}$

${ }^{46}$. Mice were weaned at 4 weeks of age and provided free access to water and standard mouse chow containing $0.8 \%$ phosphorus (Oriental MF; Oriental Yeast, Osaka, Japan).

\section{Generation of TRAP-KO mice}

331 TRAP-deficient mice were generated by gene targeting. A targeting vector was constructed by replacing the 129 genomic TRAP loci (exon1 through part of exon2) with neo ${ }^{\mathrm{r}}$ (Supplemental Fig. S1a). The targeting vector was introduced into 129 days 14 embryonic stem (ES) cells by electroporation, and clones that underwent homologous recombination were confirmed by Southern blot analysis (Supplemental Fig. S1b). Genomic DNA was extracted from tail clippings and amplified by PCR using specific primers (Supplemental Fig. S1c, Table 1). 


\section{Dietary adaptation}

For the dietary adaptation study, mice were fed a test diet based on modified AIN93G (low Pi;

0.02 or $0.1 \% \mathrm{Pi}$, control $\mathrm{Pi} ; 0.6 \% \mathrm{Pi}$, and high $\mathrm{Pi} ; 1.2 \% \mathrm{Pi}$ ), as described previously ${ }^{47-49}$.

\section{Effect of FGF23 and PTH on the regulation of NaPi transporter degradation}

343 For exogenous FGF23 expression, TransIT-EE Hydrodynamic Delivery Solution was used as the

344 TransIT in vivo gene delivery system (Takara, Osaka, Japan) as described previously ${ }^{26,27}$. For

345 PTH injection, mice were administered bovine PTH (amino acid 1-34; Sigma) at a dose of 7.5 $\mu \mathrm{g} / 100 \mathrm{~g}$ body weight, as described previously ${ }^{50,51}$.

\section{Metabolic cages to collect urine and fecal samples}

Mice were individually placed in the metabolic cages at 10:00 for quantitative urine and fecal collection for $24 \mathrm{~h}$ with free access to food and water. Fecal samples were ashed according to a modified protocol, as described previously $\mathrm{y}^{34,47,52,53}$.

\section{Biochemical measurements}

354 Concentrations of $\mathrm{Pi}, \mathrm{Ca}$, and creatinine and $\mathrm{BUN}$ were determined using commercial kits (Wako, Osaka, Japan). The fractional excretion index for $\mathrm{Ca}$ (FEICa) and Pi (FEIPi) was calculated as follows: urinary $\mathrm{Ca}$ or Pi/ (urinary creatinine /serum Ca or Pi). Concentrations of serum FGF23, plasma PTH, and $1,25(\mathrm{OH})_{2} \mathrm{D}_{3}$ were determined using the FGF23 ELISA kit (KAINOS Laboratories, Tokyo, Japan), intact PTH ELISA kit (Immunotopics Inc., San Clemente, CA, USA), and1,25-(OH) 2 Vitamin D ELISA Kit (Immundiagnostik, Bensheim, Germany), respectively. 
RNA extraction, cDNA synthesis, and quantitative PCR

Mouse tissues were sampled, immediately submerged in RNAlater (Sigma-Aldrich, St. Louis, MO, USA), and stored at $-20^{\circ} \mathrm{C}$ until use. Total cellular RNA from the sampled tissues was extracted and purified using ISOGEN (Wako, Osaka Japan) according to the manufacturer's instructions. Complementary DNA (cDNA) was synthesized as described previously ${ }^{34,47,52,53}$. The template DNA was omitted for the negative control (-) for all PCR experiments. The PCR reaction was examined without reverse transcriptase (data not shown). Quantitative PCR was performed using ABI PRISM 7500 (Applied Biosystems, Foster City, CA) as described previously $34,47,49,52,53$. The reaction mixture consisted of $10 \mu 1$ of SYBR Premix Ex Taq, ROX Reference Dye II (Perfect Real Time, Takara, Osaka, Japan) with specific primers (Table 2).

\section{Protein sample purification and immunoblotting}

BBMVs prepared using the $\mathrm{Ca}^{2+}$ precipitation method, cortical membrane, and whole homogenate were obtained from mouse kidneys and used for immunoblotting and immunoprecipitation analyses as described previously $34,49,52,53$. Protein samples were heated at $95^{\circ} \mathrm{C}$ for $5 \mathrm{~min}$ in sample buffer in the presence of 2-mercaptoethanol and subjected to sodium dodecyl sulfatepolyacrylamide gel electrophoresis (SDS-PAGE). The separated proteins were transferred by electrophoresis to Immobilon-P polyvinylidene difluoride (Millipore, Billerica, MA, USA) and treated with diluted antibodies. Signals were detected using Immobilon Western (Millipore) ${ }^{34,49,}$ $52,53$. 
Mouse kidneys were fixed with the $4 \%$ paraformaldehyde solution (pH 7.2), overnight at $4{ }^{\circ} \mathrm{C}$, washed with PBS, cryoprotected with $10 \%$ and $20 \%$ sucrose at $4{ }^{\circ} \mathrm{C}$, embedded in Tissue-Tek ${ }^{\circledR}$

Frozen sections ( $5 \mu \mathrm{m}$ thick) were collected onto MAS-coated slides (Matsunami Glass IND, Ltd., Osaka, Japan) and air-dried ${ }^{48}$. For immunofluorescence microscopy, serial frozen sections were incubated with primary antibodies overnight at $4{ }^{\circ} \mathrm{C}$. Alexa Fluor 488 anti-rabbit (Molecular Probes, Eugene, OR, USA) and Alexa Fluor 568 anti-mouse (Molecular Probes) were used as secondary antibodies for $60 \mathrm{~min}$ at room temperature ${ }^{48,49,51-53}$. Thereafter, the sections were mounted with DAPI Fluoromount $\mathrm{G}^{\mathrm{TM}}$ (Southern Biotech, Birmingham, UK). Images were taken with an A1R confocal laser scanning microscope system (Nikon, Tokyo, Japan).

\section{Immunoprecipitation}

Renal BBMVs of mice were lysed for $30 \mathrm{~min}$ at $4^{\circ} \mathrm{C}$ in TNE lysis buffer $(20 \mathrm{mM}$ Tris- $\mathrm{HCl}, 150$ $\mathrm{mM} \mathrm{NaCl}, 1 \mathrm{mM}$ EDTA, 1mM EGTA, 1\% TritonX-100, pH7.5), centrifuged for at 12,000 x g, $10 \min$ at $4^{\circ} \mathrm{C}$, and then supernatants were collected for immunoprecipitation. Immunoprecipitation samples were adjusted to $200 \mu \mathrm{g}$ proteins/ $\mathrm{ml}$ in tubes, and anti-NHERF1 (LS-C46891, LIFESPAN BIOSCIENCES, Seattle, WA, USA) or anti-TRAP antibodies were added to tubes and rotated at $4^{\circ} \mathrm{C}$ overnight. Next, protein A agarose beads (Santa Cruz Biotechnology, Dallas, TX, USA) were added to the tubes and rotated at $4{ }^{\circ} \mathrm{C}$ for $1 \mathrm{~h}$. Protein A agarose beads were centrifuged at $3000 \mathrm{x}$ g for $1 \mathrm{~min}$ at $4^{\circ} \mathrm{C}$ and washed with TNE lysis buffer 4 times before removing the supernatant and eluting in SDS sample buffer. Loading samples were heated at $95^{\circ} \mathrm{C}$ for $5 \mathrm{~min}$ and then analyzed by SDS-PAGE using antibodies against NHERF1, TRAP, and NaPi2a. 
Rabbit anti-NaPi2a and NaPi2c polyclonal antibodies were generated as described previously and

411 used for immunoblotting and immunohistochemistry ${ }^{7,48,51,52}$. Rabbit anti-TRAP polyclonal antibodies were generated against mouse TRAP C-terminal fragments in rabbits as described previously ${ }^{54}$. Briefly, purified GST-TRAP C-terminal (residues 90-243) fusion proteins were used as antigens in rabbits. The purified IgG fractions were obtained from serums of the immunized animals. Mouse anti-actin monoclonal antibodies (Millipore) were used as an internal control. Horseradish peroxidase-conjugated anti-rabbit or anti-mouse IgG was utilized as the secondary antibody (Jackson Immuno Research Laboratories, Inc, West Grove, PA, USA). The diluted antibodies for immunoblotting were as follows: anti-NaPi2a (1:15000), anti-NaPi2c (1:1500), anti-TRAP (1:1000), and anti-actin (1:10000). The diluted antibodies for immunofluorescence staining were as follows: anti-NaPi2a (1:500), anti-NaPi2c (1:1000), anti-TRAP (1:200), antivillin (Millipore; 1:300), and anti-NHERF1 (LIFESPAN BIOSCIENCES; 1:1000).

\section{Bone analysis}

424 Histochemical analysis was performed as described previously ${ }^{34,55}$. The femora of all the groups were fixed with $4 \%$ paraformaldehyde overnight at $4{ }^{\circ} \mathrm{C}$, decalcified for 4 weeks with $10 \%$ EDTA, and then embedded into paraffin for immunohistochemical examinations. For von Kossa staining, tibiae were immersed in a mixture containing $2 \%$ paraformaldehyde and $2.5 \%$ glutaraldehyde diluted in a $0.067 \mathrm{M}$ cacodylate buffer ( $\mathrm{pH} 7.4$ ) and post-fixed with $1 \%$ osmium tetroxide in a $0.067 \mathrm{M}$ cacodylate buffer for $4 \mathrm{hr}$ at $4{ }^{\circ} \mathrm{C}$. After post-fixation, the tibiae were embedded in epoxy resin (Epon 812, Taab, Berkshire, UK) and sliced to semithin sections with $500 \mathrm{~nm}$ thickness using an ultramicrotome (Sorvall MT-5000; Ivan Sorvall, Inc., Norwalk, CT). Epoxy resin slides 
brown/black staining of the bone tissue was discernible under light microscopy.

Immunohistochemical analyses of mouse bone sections were performed as described previously. Briefly, the sections were immersed into $0.3 \% \mathrm{H}_{2} \mathrm{O}_{2}$ in methanol for 30 min to block endogenous peroxidase. To reduce nonspecific binding, $1 \%$ bovine serum albumin (BSA; Serologicals Proteins Inc., Kankakee, IL, USA) in PBS (1\% BSA-PBS) was applied to the sections for $20 \mathrm{~min}$. The sections were then incubated with rabbit polyclonal antisera against tissue-nonspecific ALP diluted at 1:200 ${ }^{56}$. A general method for rapid purification of soluble versions of glycosylphosphatidylinositol-anchored proteins expressed in insect cells: an application for human tissue-nonspecific alkaline phosphatase or rabbit polyclonal anti-dentin matrix protein-1 (Takara Bio, Shiga, Japan) diluted at 1:200 with 1\% BSA-PBS at room temperature for $2 \mathrm{~h}$. The treated sections were incubated with horseradish peroxidase-conjugated anti-rabbit IgG antibody (Chemicon International, Temecula, CA, USA) for $1 \mathrm{~h}$, and the immunoreactivities were visualized by using diaminobenzidine tetrahydrochloride as a substrate. For double detection of ALP and tartrate-resistant acid phosphatase, the sections immunodetected for ALP were incubated in a mixture of $8 \mathrm{mg}$ of naphthol AS-BI phosphate (Sigma-Aldrich), 70 $\mathrm{mg}$ of red violet LB salt (Sigma-Aldrich), and $50 \mathrm{mM} \mathrm{L} \mathrm{(+)} \mathrm{tartaric} \mathrm{acid} \mathrm{(0.76} \mathrm{g;} \mathrm{Nacalai} \mathrm{Tesque,}$ Kyoto, Japan) diluted in $60 \mathrm{ml}$ of a $0.1 \mathrm{M}$ sodium acetate buffer (pH 5.0) for $20 \mathrm{~min}$ at room temperature. Methyl green was used for counterstaining in all sections.

\section{Statistical Analysis}

Data are expressed as means \pm SE. Differences among multiple groups were analyzed by analysis of variance followed by the Scheffe test. Differences between 2 experimental groups were established by analysis of variance followed by Student's $t$ test. A $P$ value of less than 0.05 was considered significant. 


\section{Acknowledgments}

The technical assistance of Kanokporn Phetdee, Yuka Kawabata and Shogo Nakayama is gratefully acknowledged. We also thank Ryo Hatano for research advice. This study was supported by the Support Center for Advanced Medical Sciences, Tokushima University Graduate School of Biomedical Sciences. This work was supported by JSPS KAKENHI Grants (JP17H04190, JP20K08637 to K.M., JP15K08274, JP21H03365 to S.N, JP24390217 to Y.K., JP21H03375 to H.S.), and The Salt Science Research Foundation (No. 2130 to H.S.).

\section{Author contributions}

467 Conceived of and designed the research; S.N., Y.K., K.M., and H.S. Performed the experiments; manuscript; Y.S., H.S., and K.M. Reviewed and approved manuscript; K.M., T.H., N.A., S.N., Y.K., and H.S.

\section{Competing interests}

474 The authors declare no competing interests

\section{$475 \quad$ Additional information}

Supplementary Information 


\section{References}

483 1. Hernando N, Gagnon K, Lederer E. Phosphate Transport in Epithelial and Nonepithelial Tissue. Physiol Rev 2021; 101: 1-35.

2. Lederer E, Miyamoto K. Clinical consequences of mutations in sodium phosphate

4. Ho BB, Bergwitz C. FGF23 signalling and physiology. J Mol Endocrinol 2021; 66: R23R32.

494

5. Lederer E. Regulation of serum phosphate. J Physiol 2014; 592: 3985-3995.

6. Beck L, Karaplis AC, Amizuka N, et al. Targeted inactivation of Npt2 in mice leads to severe renal phosphate wasting, hypercalciuria, and skeletal abnormalities. Proc Natl Acad Sci U S A 1998; 95: 5372-5377.

8. Gisler SM, Stagljar I, Traebert M, et al. Interaction of the type IIa Na/Pi cotransporter

9. Hernando N, Deliot N, Gisler SM, et al. PDZ-domain interactions and apical expression

10. Ketchem CJ, Khundmiri SJ, Gaweda AE, et al. Role of $\mathrm{Na}+\mathrm{H}+$ exchanger regulatory factor 1 in forward trafficking of the type IIa Na+-Pi cotransporter. Am J Physiol Renal 
transport by phosphorylation of serine 77 of sodium-hydrogen exchanger regulatory factor-1. J Clin Invest 2007; 117: 3412-3420.

12. Weinman EJ, Steplock D, Zhang Y, et al. Cooperativity between the phosphorylation of Thr95 and Ser77 of NHERF-1 in the hormonal regulation of renal phosphate transport. $J$ Biol Chem 2010; 285: 25134-25138.

13. Déliot N, Hernando N, Horst-Liu Z, et al. Parathyroid hormone treatment induces dissociation of type IIa Na+-P(i) cotransporter-Na+/H+ exchanger regulatory factor-1 complexes. Am J Physiol Cell Physiol 2005; 289: C159-167.

14. Obayashi T, Hayashi S, Shibaoka M, et al. COXPRESdb: a database of coexpressed gene networks in mammals. Nucleic Acids Res 2008; 36: D77-82.

15. Okamura Y, Aoki Y, Obayashi T, et al. COXPRESdb in 2015: coexpression database for animal species by DNA-microarray and RNAseq-based expression data with multiple quality assessment systems. Nucleic Acids Res 2015; 43: D82-86.

16. Obayashi T, Kagaya Y, Aoki Y, et al. COXPRESdb v7: a gene coexpression database for 11 animal species supported by 23 coexpression platforms for technical evaluation and evolutionary inference. Nucleic Acids Res 2019; 47: D55-d62.

17. Ovens K, Eames BF, McQuillan I. Comparative Analyses of Gene Co-expression Networks: Implementations and Applications in the Study of Evolution. Front Genet 2021; 12: 695399.

18. Wang P, Sun B, Hao D, et al. Human TMEM174 that is highly expressed in kidney tissue activates AP-1 and promotes cell proliferation. Biochem Biophys Res Commun 2010; 394: 993-999.

19. Zhang X, Hu F, Meng L, et al. Analysis of TMEM174 gene expression in various renal cancer types by RNA in situ hybridization. Oncol Lett 2014; 8: 1693-1696.

20. Hu F, Meng Y, Gou L, et al. Analysis of promoters and CREB/AP-1 binding sites of the human TMEM174 gene. Exp Ther Med 2013; 6: 1290-1294. 
21. Toro L, Barrientos V, León P, et al. Erythropoietin induces bone marrow and plasma fibroblast growth factor 23 during acute kidney injury. Kidney Int 2018; 93: 1131-1141.

22. Biber J, Gisler SM, Hernando N, et al. PDZ interactions and proximal tubular phosphate reabsorption. Am J Physiol Renal Physiol 2004; 287: F871-875.

23. Biber J, Gisler SM, Hernando N, et al. Protein/protein interactions (PDZ) in proximal tubules. J Membr Biol 2005; 203: 111-118.

24. Hernando N, Gisler SM, Reining SC, et al. NaPi-IIa interacting proteins and regulation of renal reabsorption of phosphate. Urol Res 2010; 38: 271-276.

25. Segawa H, Kawakami E, Kaneko I, et al. Effect of hydrolysis-resistant FGF23-R179Q on dietary phosphate regulation of the renal type-II Na/Pi transporter. Pflugers Arch 2003; 446: 585-592.

26. Inoue Y, Segawa H, Kaneko I, et al. Role of the vitamin D receptor in FGF23 action on phosphate metabolism. Biochem J 2005; 390: 325-331.

27. Tomoe Y, Segawa H, Shiozawa K, et al. Phosphaturic action of fibroblast growth factor 23 in Npt2 null mice. Am J Physiol Renal Physiol 2010; 298: F1341-1350.

28. Keusch I, Traebert M, Lotscher M, et al. Parathyroid hormone and dietary phosphate provoke a lysosomal routing of the proximal tubular $\mathrm{Na} / \mathrm{Pi}$-cotransporter type II. Kidney Int 1998; 54: 1224-1232.

29. Andrukhova O, Zeitz U, Goetz R, et al. FGF23 acts directly on renal proximal tubules to induce phosphaturia through activation of the ERK1/2-SGK1 signaling pathway. Bone 2012; 51: 621-628.

30. Abou-Samra AB, Jüppner H, Force T, et al. Expression cloning of a common receptor for parathyroid hormone and parathyroid hormone-related peptide from rat osteoblastlike cells: a single receptor stimulates intracellular accumulation of both cAMP and inositol trisphosphates and increases intracellular free calcium. Proc Natl Acad Sci U S A 1992; 89: 2732-2736. 
588

589

590

591

592

593

594

595

596

597

598

599

600

601

602

603

604

605

606

607

608

609

610

611

612

613

614

615

616

617

618

619

620

621

622

623

31. Traebert M, Volkl H, Biber J, et al. Luminal and contraluminal action of 1-34 and 3-34 PTH peptides on renal type IIa Na-P(i) cotransporter. Am J Physiol Renal Physiol 2000; 278: F792-798.

32. Villa-Bellosta R, Barac-Nieto M, Breusegem SY, et al. Interactions of the growth-related, type IIc renal sodium/phosphate cotransporter with PDZ proteins. Kidney Int 2008; 73: 456-464.

33. Giral H, Lanzano L, Caldas Y, et al. Role of PDZK1 protein in apical membrane expression of renal sodium-coupled phosphate transporters. J Biol Chem 2011; 286: 15032-15042.

34. Kaneko I, Segawa H, Ikuta K, et al. Eldecalcitol Causes FGF23 Resistance for Pi Reabsorption and Improves Rachitic Bone Phenotypes in the Male Hyp Mouse. Endocrinology 2018; 159: 2741-2758.

35. Liu S, Zhou J, Tang W, et al. Pathogenic role of Fgf23 in Hyp mice. Am J Physiol Endocrinol Metab 2006; 291: E38-49.

36. Murali SK, Andrukhova O, Clinkenbeard EL, et al. Excessive Osteocytic Fgf23 Secretion Contributes to Pyrophosphate Accumulation and Mineralization Defect in Hyp Mice. PLoS Biol 2016; 14: e1002427.

37. Christov M, Waikar SS, Pereira RC, et al. Plasma FGF23 levels increase rapidly after acute kidney injury. Kidney Int 2013; 84: 776-785.

38. Kuro OM. Phosphate and Klotho. Kidney Int 2011; 79121: S20-23.

39. Kuro OM. The FGF23 and Klotho system beyond mineral metabolism. Clin Exp Nephrol 2017; 21: 64-69.

40. Erben RG, Andrukhova O. FGF23-Klotho signaling axis in the kidney. Bone 2017; 100: $62-68$.

41. Shimamura Y, Hamada K, Inoue K, et al. Serum levels of soluble secreted $\alpha$-Klotho are decreased in the early stages of chronic kidney disease, making it a probable novel 
biomarker for early diagnosis. Clin Exp Nephrol 2012; 16: 722-729.

42. Koh N, Fujimori T, Nishiguchi S, et al. Severely reduced production of klotho in human chronic renal failure kidney. Biochem Biophys Res Commun 2001; 280: 1015-1020.

43. Segawa H, Yamanaka S, Ohno Y, et al. Correlation between hyperphosphatemia and type II Na-Pi cotransporter activity in klotho mice. Am J Physiol Renal Physiol 2007; 292: F769-779.

44. Morishita K, Shirai A, Kubota M, et al. The progression of aging in klotho mutant mice can be modified by dietary phosphorus and zinc. $J$ Nutr 2001; 131: 3182-3188.

45. Martins JS, Liu ES, Sneddon WB, et al. 1,25-Dihydroxyvitamin D Maintains Brush Border Membrane NaPi2a and Attenuates Phosphaturia in Hyp Mice. Endocrinology 2019; 160: 2204-2214.

46. Segawa H, Onitsuka A, Kuwahata M, et al. Type IIc sodium-dependent phosphate transporter regulates calcium metabolism. J Am Soc Nephrol 2009; 20: 104-113.

47. Sasaki S, Segawa H, Hanazaki A, et al. A Role of Intestinal Alkaline Phosphatase 3 (Akp3) in Inorganic Phosphate Homeostasis. Kidney Blood Press Res 2018; 43: 14091424.

48. Segawa $\mathrm{H}$, Yamanaka S, Ito M, et al. Internalization of renal type IIc Na-Pi cotransporter in response to a high-phosphate diet. Am J Physiol Renal Physiol 2005; 288: F587-596.

49. Ikuta K, Segawa H, Hanazaki A, et al. Systemic network for dietary inorganic phosphate adaptation among three organs. Pflugers Arch 2019; 471: 123-136.

50. Fujii T, Segawa H, Hanazaki A, et al. Role of the putative PKC phosphorylation sites of the type IIc sodium-dependent phosphate transporter in parathyroid hormone regulation. Clin Exp Nephrol 2019; 23: 898-907.

51. Segawa H, Yamanaka S, Onitsuka A, et al. Parathyroid hormone-dependent endocytosis of renal type IIc Na-Pi cotransporter. Am J Physiol Renal Physiol 2007; 292: F395-403. 
660

661

662

663

664

665

666

667

668

669

670

671

672

673

674

675

676

677

678

679

680

681

682

683

684

685

686

687

688

689

690

52. Hanazaki A, Ikuta K, Sasaki S, et al. Role of sodium-dependent Pi transporter/Npt2c on Pi homeostasis in klotho knockout mice different properties between juvenile and adult stages. Physiol Rep 2020; 8: e14324.

53. Ikuta K, Segawa H, Sasaki S, et al. Effect of Npt2b deletion on intestinal and renal inorganic phosphate (Pi) handling. Clin Exp Nephrol 2018; 22: 517-528.

54. Nagamori S, Wiriyasermkul $\mathrm{P}$, Guarch ME, et al. Novel cystine transporter in renal proximal tubule identified as a missing partner of cystinuria-related plasma membrane protein rBAT/SLC3A1. Proc Natl Acad Sci U S A 2016; 113: 775-780.

55. Hasegawa T, Yamamoto T, Sakai S, et al. Histological Effects of the Combined Administration of Eldecalcitol and a Parathyroid Hormone in the Metaphyseal Trabeculae of Ovariectomized Rats. J Histochem Cytochem 2019; 67: 169-184.

56. Oda K, Amaya Y, Fukushi-Irie M, et al. A general method for rapid purification of soluble versions of glycosylphosphatidylinositol-anchored proteins expressed in insect cells: an application for human tissue-nonspecific alkaline phosphatase. J Biochem 1999; 126: 694-699. 
692 Table 1 Primers for genotyping PCR

Primer name Sequences (5'-3')

Primer 1 ACATTCATCCTGATCGCTGTGTG

Primer 2 CGTGCAATCCATCTTGTTCAAT

Primer 3 GgaATTAACCAGgGCAGCTTAA

\begin{tabular}{lll} 
Primer & Sense (Sequences; 5'-3') $^{\prime}$ & Antisense (Sequences; ${ }^{\prime}$ '-3') \\
\hline Cyp24A1 & TGGGAAGATGATGGTGACCC & TCGATGCAGGGCTTGACTG \\
Cyp27B1 & GAGCAAACTCCAGGAAGCAG & TGAGGAATGATCAGGAGAGG \\
Mouse FGF23 & CCATCTACAGTGCCCTGATG & GCTGAAGTGAAGCGATCC \\
GAPDH & CTGCACCACCAACTGCTTAGC & CATCCACAGTCTTCTGGGTG \\
Human FGF23 & GCTCTGGGTCTGTGCCTTGT & GTGATACTGAGGAGAGTG \\
-kilotho & CAATGGCTTTCCTCCTTTAC & TGCACATCCCACAGATAGAC \\
PTH & TGAGAGTCATTGTATGTAAAGATGAGGTGTTTGCCCAGGTTG \\
slc34a1 & AGTCTCATTCGGATTTGGTGTCA & GCCGATGGCCTCTACCCT \\
slc34a3 & TAATCTTCGCAGTTCAGGTTGCT & CAGTGGAATTGGCAGTCTCAA \\
Tmem174/TRAP & GCCACTTTGCTTTTCTCAGG & GGGACCCTCTCCTCGTTATC \\
\hline
\end{tabular}


Figure legends

Figure 1 Genes co-expressed with renal slc34a NaPi transporters

The genes co-expressed with slc34a1 or slc34a3 were identified by database search on COEXPRESdb, as listed in Table 1 and 2. Correlation profile of gene expression between (a) slc34a1 (x axis: probe ID 1423279_at), or (b) slc34a3 (x axis: probe ID 1439519_at), and TMEM174 (y axis: probe ID 1435201).

Figure 2 Tissue localization of TRAP expression and possible involvement in Pi homeostasis.

(a) TRAP mRNA level in several tissues of wild-type (WT) mice by real-time PCR. Male mice at 8 weeks of age $(n=5-9)$ were used. Glyceraldehyde-3-phosphate dehydrogenase (GAPDH) was used as an internal control. Values are mean \pm SE. (b) Immunofluorescence staining TRAP (green) in renal section of 8-week-old WT mice. DAPI (blue), Villin (red). Sections were prepared from mouse kidney embedded in OCT compound and frozen. (c, d) Western blotting analyses of the renal brush border membrane vesicles (BBMVs) isolated from the WT mice $(n=3-5)$ fed a low Pi (LP: 0.02\%), control Pi (CP: 0.6\%), and high Pi (HP: 1.2\%) diet. Each lane was loaded with 20 $\mu \mathrm{g}$ of BBMVs. Actin was used as an internal control. Values are mean \pm SE. ${ }^{\mathrm{a}} p<0.05,{ }^{\mathrm{a}} p<0.01 \mathrm{vs}$. LP. Experiments were performed in triplicate. (e) Western blotting analysis of the renal BBMVs isolated from the kidney of 8-week-old NaPi2 $\mathrm{a}^{+/+} \mathrm{NaPi} 2 \mathrm{c}^{+/+}, \mathrm{NaPi}_{2} \mathrm{a}^{-/}$, and NaPi2 $\mathrm{c}^{-/-}$mice $(\mathrm{n}=3-$ 5). Each lane was loaded with $20 \mu \mathrm{g}$ of BBMVs. Actin was used as an internal control. Values are mean \pm SE. ${ }^{a} p<0.05$ vs. $\mathrm{NaPi} 2 \mathrm{a}^{+/+} \mathrm{NaPi} 2 \mathrm{c}^{+/+}$mice. Experiments were repeated at least 3 times.

722 Figure 3 Characteristics of TRAP ${ }^{-/-}$mice.

723 Expression of TRAP mRNA and protein in $\mathrm{TRAP}^{+/+}, \mathrm{TRAP}^{+/}$, and $\mathrm{TRAP}^{-/-}$mice. PCR and 
Western blotting analysis in the kidney of mice. (a) Aliquots of each PCR product were electrophoresed on a 1.5\% agarose gel. Glyceraldehyde-3-phosphate dehydrogenase (GAPDH) was used as the internal control. (b) Western blotting analysis of BBMVs isolated from the kidneys of $\mathrm{TRAP}^{+/+}, \mathrm{TRAP}^{+/}$, and $\mathrm{TRAP}^{-/-}$mice. Each lane was loaded with $20 \mu \mathrm{g}$ of BBMV. Actin was used as the internal control. (c) Growth curves for male and female TRAP ${ }^{+/+}$, TRAP $^{+/}$, and $\mathrm{TRAP}^{-/ /}$mice. Values are mean $\pm \mathrm{SE}(\mathrm{n}=10-30) .{ }^{*} p<0.05$ vs. $\mathrm{TRAP}^{+/+},{ }^{\sharp} p<0.05$ vs. $\mathrm{TRAP}^{+/-}$ mice. Metabolic cages were used for measurement of 24-h food intake (g/ day), and collection of urine, and feces from mice. (d) Food intake, (e) plasma creatinine, (f) plasma blood urea nitrogen, (g) blood ionized $\mathrm{Ca}$, (h) fecal Ca excretion, (i) urinary Ca excretion, (j) plasma $\mathrm{Pi}$, (k) fecal Pi excretion, (1) urinary Pi excretion. Male $\mathrm{TRAP}^{+/+}, \mathrm{TRAP}^{+/-}$, and $\mathrm{TRAP}^{-/-}$mice at $8-9$ weeks of age $(\mathrm{n}=30-50)$. Values are mean \pm SE.

Figure 4 Effects of Deletion of TRAP on Pi homeostasis

(a-c) Plasma1,25(OH) $)_{2} \mathrm{D}_{3}$, plasma intact PTH, serum intact FGF23 levels of Male RRAP $^{+/+}$, $\mathrm{TRAP}^{+/}$, and $\mathrm{TRAP}^{-/-}$mice at $8-9$ weeks of age. Values are mean $\pm \mathrm{SE}(\mathrm{n}=10-20) .{ }^{\mathrm{a}} p<0.01 \mathrm{vs}$. TRAP $^{+/+}$mice. ${ }^{b^{\prime}} p<0.01$ vs. TRAP ${ }^{+/-}$mice. (d-g) Real-time PCR analysis. GAPDH was used as an internal control. Values are mean $\pm \mathrm{SE}(\mathrm{n}=10-15) .{ }^{\mathrm{a}} p<0.01$ vs. $\mathrm{TRAP}^{+/+}$mice. ${ }^{\mathrm{b}} p<0.01$ vs. TRAP $^{+/-}$mice. ${ }^{\# \prime} p<0.01$. (h) Immunohistochemistry of FGF23 (brown color) in metaphyseal and diaphysis trabeculae bones of $\mathrm{TRAP}^{+/+}$and $\mathrm{TRAP}^{-/-}$male mice (8-week-old). Arrows: osteoblast/preosteoblast, arrow head: osteocyte.

746 Histological analysis of longitudinal femoral sections of 8-week-old $\mathrm{TRAP}^{+/+}$and $\mathrm{TRAP}^{-/ /}$mice. (a) Hematoxylin/eosin staining, (b) Double staining of alkaline phosphatase (brown color) and 
tartrate-resistant acid phosphatase (red color), (c) von Kossa staining of metaphyseal trabeculae.

\section{Figure 6 Deletion of TRAP and renal NaPi transporters}

(a) Western blot analysis of $\mathrm{NaPi}$ transporters in $\mathrm{TRAP}^{+/+}$and $\mathrm{TRAP}^{-/-}$mice (8-week-old mice, Immunofluorescence staining of $\mathrm{NaPi} 2 \mathrm{a}$ or $\mathrm{NaPi} 2 \mathrm{c}$ (green) in renal sections of 8-week-old $\mathrm{TRAP}^{+/+}$and $\mathrm{TRAP}^{-/-}$mice. DAPI (blue), Villin (red). Sections were prepared from kidneys embedded in the OCT compound and frozen. Scale bar; $100 \mu \mathrm{m}$. (c-d) Western blotting analysis of FGFR, $\alpha$-Klotho (c), and total ERK1/2/phosphorylation ERK1/2 (d) levels. Each lane was loaded with $20 \mu \mathrm{g}$ of cortical membranes (c) or whole homogenate (d). Actin was used as an internal control. Values are mean \pm SE. ${ }^{\prime \prime} p<0.01$. Experiments were repeated at least 3 times.

Figure 7 Scaffold protein levels in TRAP $^{-/-}$mice.

762 Western blot analysis of scaffold proteins in $\mathrm{TRAP}^{+/+}$and $\mathrm{TRAP}^{-/-}$mice fed normal mouse chow.

763 Each lane was loaded with $20 \mu \mathrm{g}$ of renal whole homogenate (a) and BBMVs (b). Actin was used 764 as an internal control. Values are mean \pm SE. ${ }^{\#} p<0.05$. Immunoprecipitation of NHERF1 (c) or

765 TRAP (d) from renal BBMV lysates of WT, TRAP-KO and NaPi2a-KO mice fed the normal mouse chow and immunoblotting with anti-TRAP, -NaPi2a or -NHERF1 antibodies. Arrow indicates the TRAP. Experiments were repeated at least 3 times. 
${ }^{\#} p<0.05,{ }^{\# \prime} p<0.01$ vs same diet, ${ }^{\mathrm{a}} p<0.05,{ }^{\mathrm{a}} p<0.01$ vs LP, ${ }^{\mathrm{b}} p<0.01$ vs. CP of same genotype. (c) Western blotting analyses. Each lane was loaded with $20 \mu \mathrm{g}$ of BBMVs. Actin was used as an internal control. Values are mean \pm SE. ${ }^{\#} p<0.05,{ }^{\#} p<0.01$. (d) Immunostaining of renal NaPi2a (Green) localization in the kidney sections of mice fed the LP $(0.02 \% \mathrm{Pi})$ and HP $(1.2 \% \mathrm{Pi})$ diet for 7 days. DAPI (Blue), Villin (Red). Experiments were performed in triplicate.

\section{Figure 9 Abnormal regulation of phosphaturic action to renal NaPi2a Pi transporter in} TRAP $^{-/}$mice.

$\mathrm{TRAP}^{+/+}$and $\mathrm{TRAP}^{-/}$mice (9-10-week-old mice, $\mathrm{n}=3-5$, respectively) were fed a $0.02 \%$ low $\mathrm{Pi}$ diet for 7 days to reduce endogenous FGF23. Exogenous FGF23 expression was performed using the Naked-DNA method, as described previously ${ }^{27}$. (a) Western blotting analysis of total ERK1/2 and phosphorylation ERK1/2 in $\mathrm{TRAP}^{+/+}$and $\mathrm{TRAP}^{-/-}$mice. Each lane was loaded with $20 \mu \mathrm{g}$ of the whole homogenate. Values are mean \pm SE. ${ }^{*} p<0.05$ vs control of the same genotype, ${ }^{*} p<0.01$ vs same treatment of TRAP ${ }^{+/+}$mice. ns; not significant. (b) FEIPi. Values are mean \pm SE. ${ }^{\#} p<0.05$ vs control of the same genotype. (c) Western blot analysis of $\mathrm{NaPi}$ transporters in $\mathrm{TRAP}^{+/+}$and $\mathrm{TRAP}^{-/-}$mice. Each lane was loaded with $20 \mu \mathrm{g}$ of BBMVs. Actin was used as an internal control. ${ }^{*}, p<0.01$ vs same treatment of $\mathrm{TRAP}^{+/+}$mice. Values are mean \pm SE. ${ }^{\# \prime} p<0.01$ vs control of the same genotype. ns; not significant. Experiments were performed in triplicate.

$\mathrm{TRAP}^{+/+}$and $\mathrm{TRAP}^{-/-}$mice (9-10-week-old mice, $\mathrm{n}=3-5$, respectively) were fed a $0.1 \%$ low Pi diet for 7 days to reduce endogenous PTH. Bovine PTH (1-34) was administered to $\mathrm{TRAP}^{+/+}$and $\mathrm{TRAP}^{-/}$mice. Samples were collected after $15 \mathrm{~min}$ or $1 \mathrm{~h}$ administration of PTH. (d) cAMP level of the kidney of mice after 15 min PTH administration. (e) FEICa, (f) FEIPi. Samples were collected after $1 \mathrm{~h}$ administration of PTH. Values are mean \pm SE. ${ }^{*} p<0.05$ vs 
control of the same genotype. ${ }^{*}, p<0.01$ vs same treatment of TRAP ${ }^{+/+}$mice. ns; not significant.

(g) Western blot analysis of NaPi2a in $\mathrm{TRAP}^{+/+}$and $\mathrm{TRAP}^{-/-}$mice. Each lane was loaded with 20 $\mu \mathrm{g}$ of BBMVs. Actin was used as an internal control. Values are mean $\pm \mathrm{SE}$. \#' $p<0.01$ vs control of the same genotype. ${ }^{* \prime} p<0.01$ vs same treatment of TRAP ${ }^{+/+}$mice. ns; not significant. (h) Immunostaining of renal NaPi2a (Green) localization in the kidney sections of mice 15 min and $1 \mathrm{~h}$ after administration of PTH. DAPI (Blue). Villin (Red). Experiments were performed in triplicate.

\section{Figure 10 Renal injury in TRAP $^{-/}$mice}

Male $\mathrm{TRAP}^{+/+}$and TRAP ${ }^{-/-}$mice (n=10-30) were administered folic acid (FA; $\left.240 \mu \mathrm{g} / \mathrm{kg} \mathrm{BW}\right)$. and serum intact FGF23 at $24 \mathrm{~h}$ (f) and 7 days (g) after administration of FA. Values are mean \pm SE. ${ }^{\#} p<0.05, \#^{\prime}<0.01$ vs vehicle of the same genotype, ${ }^{*} p<0.05$ vs same treatment of $\mathrm{TRAP}^{+/+}$ mice. ns; not significant. (h) Western blotting analysis of NaPi2a. Each lane was loaded with 20 $\mu \mathrm{g}$ of renal BBMVs of mice $24 \mathrm{~h}$ after administration of FA. Actin was used as an internal control.

\section{Figure 11 The putative role of TRAP in the control of plasma Pi levels}

813 TRAP interacts with NaPi2a and is involved in internalization by PTH and FGF23. Under a high

814 Pi load, urinary Pi excretion is enhanced by internalization of NaPi2a induced by PTH and FGF23, and hyperphosphatemia is prevented. In TRAP-KO mice, internalization of NaPi2a is resistant to PTH and FGF23. As a result, Pi reabsorption is maintained, and plasma Pi concentration increases.

817 TRAP is expected to be a molecule that is associated with both the induction of phosphaturic 818 hormone (FGF23) and the regulation of NaPi2a in the proximal tubules. G; glomerulus, PT; 819 proximal tubule. 
$12 / 13 / 21$

820 
Figure 1

a

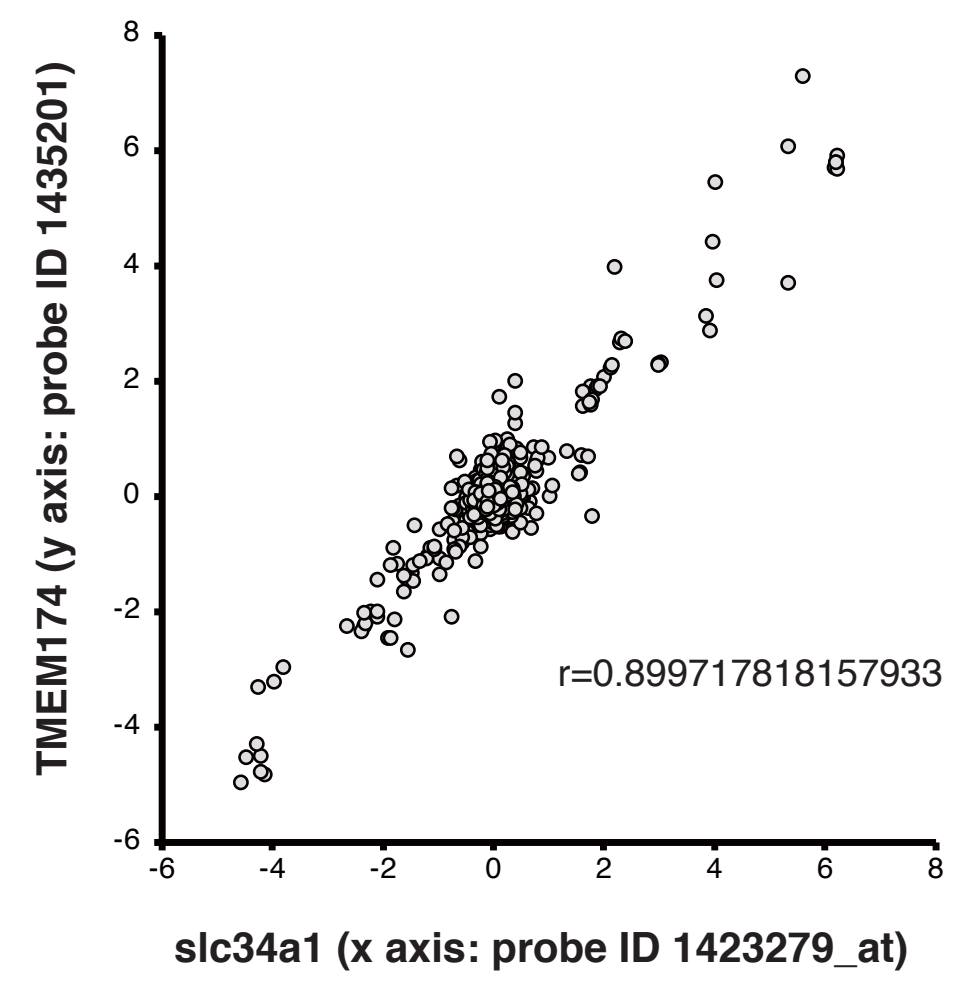

b

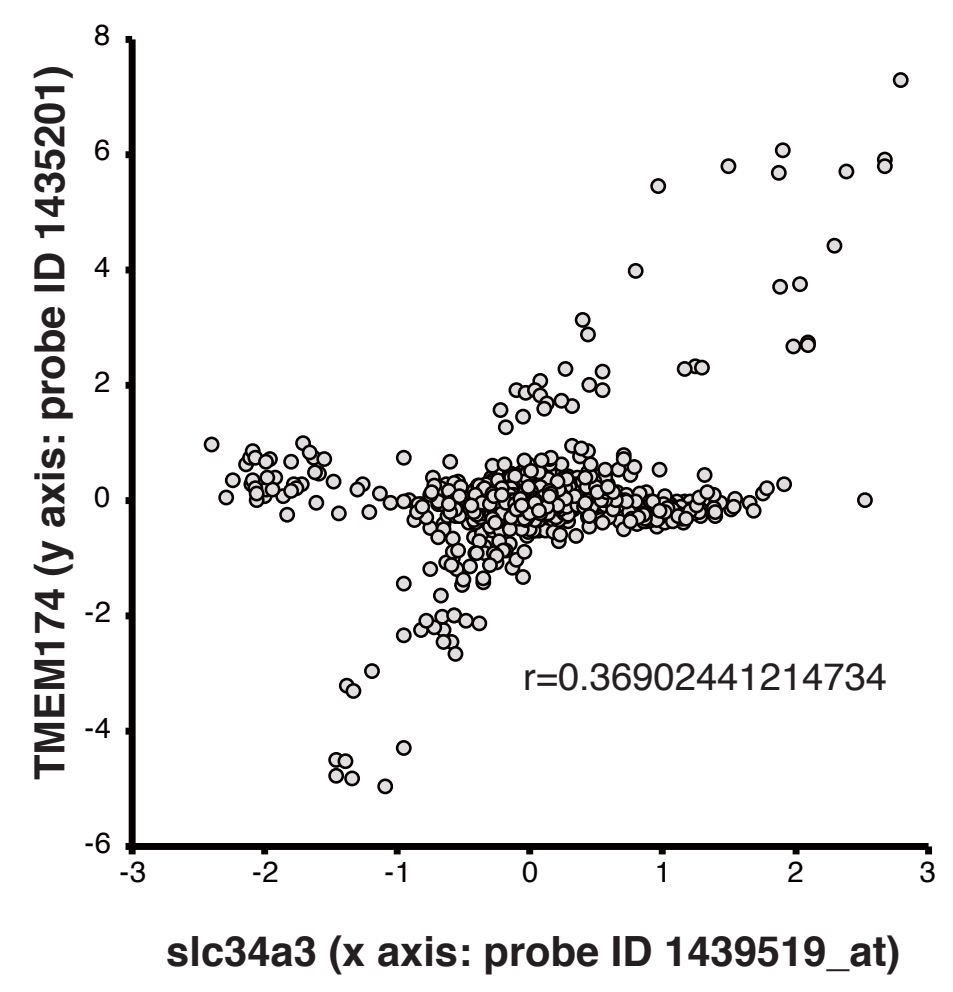


Figure 2
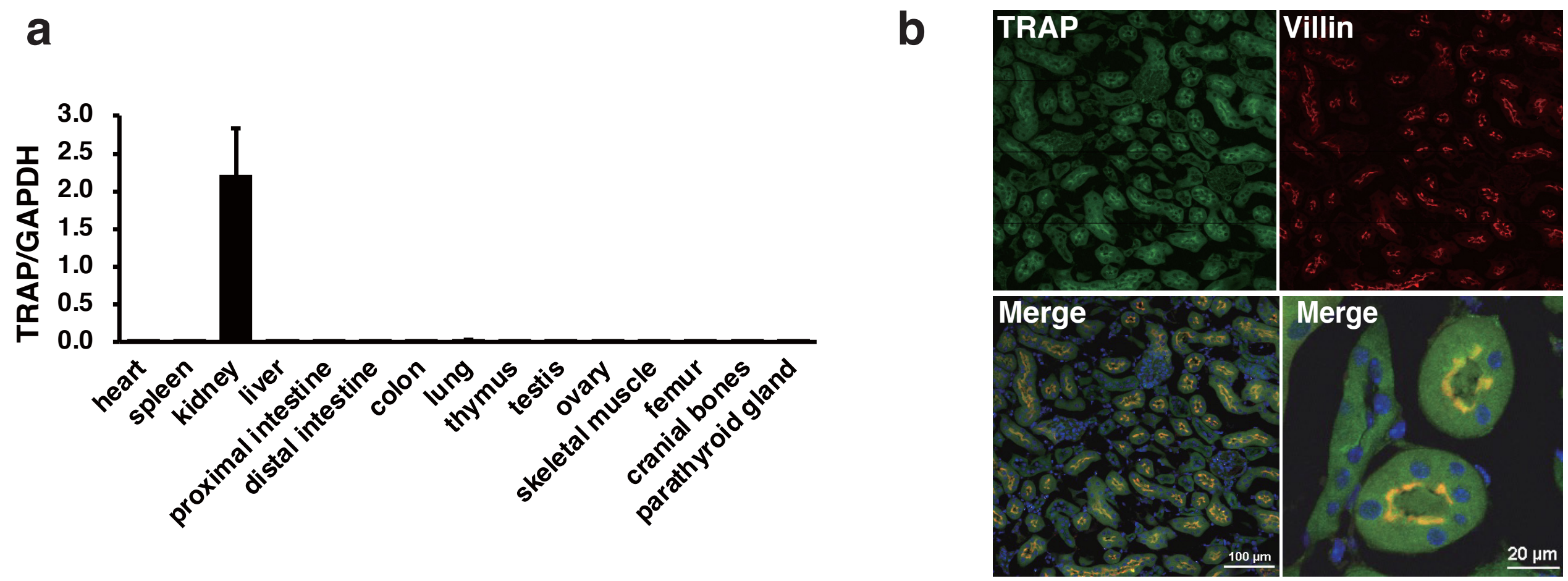

C
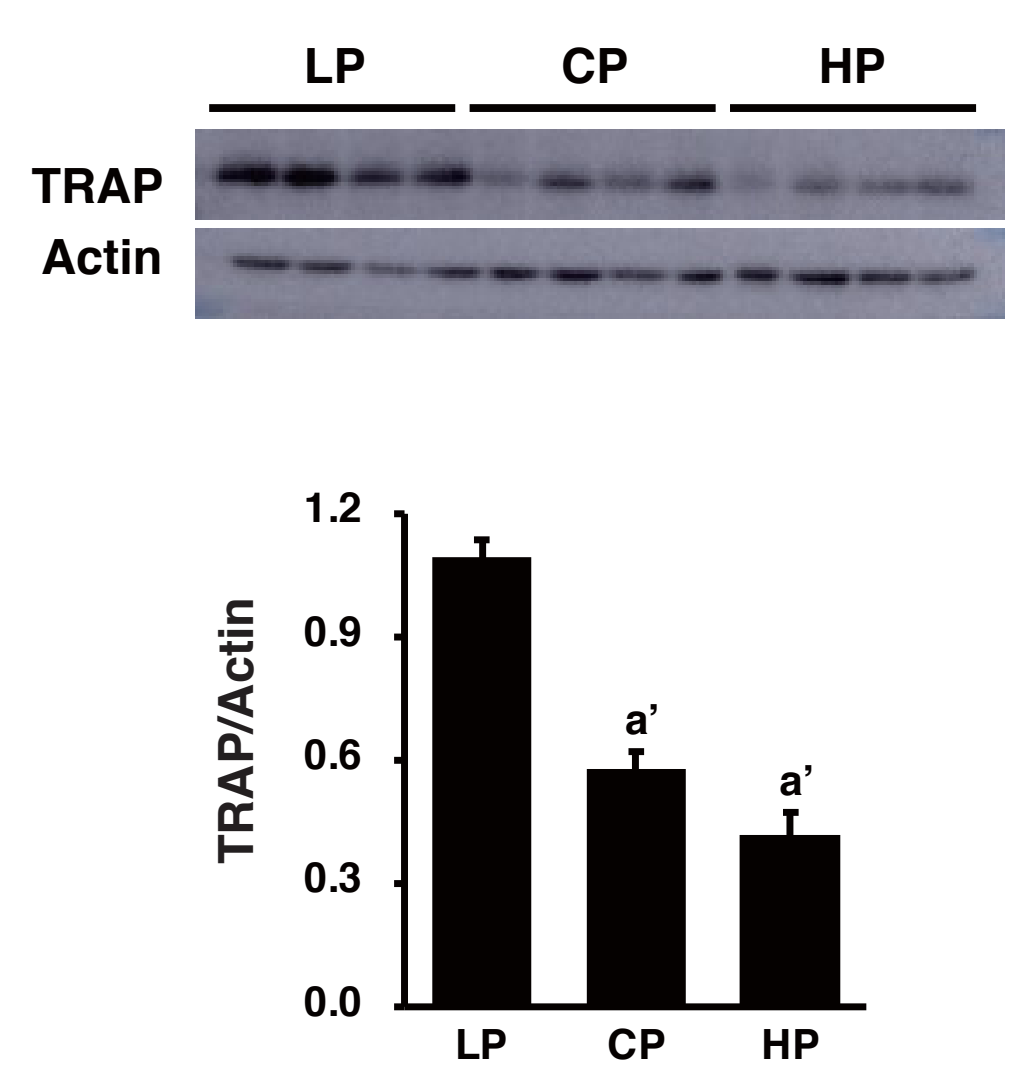

d

NaPi2a

$\mathrm{NaPi2c}$

Actin

e
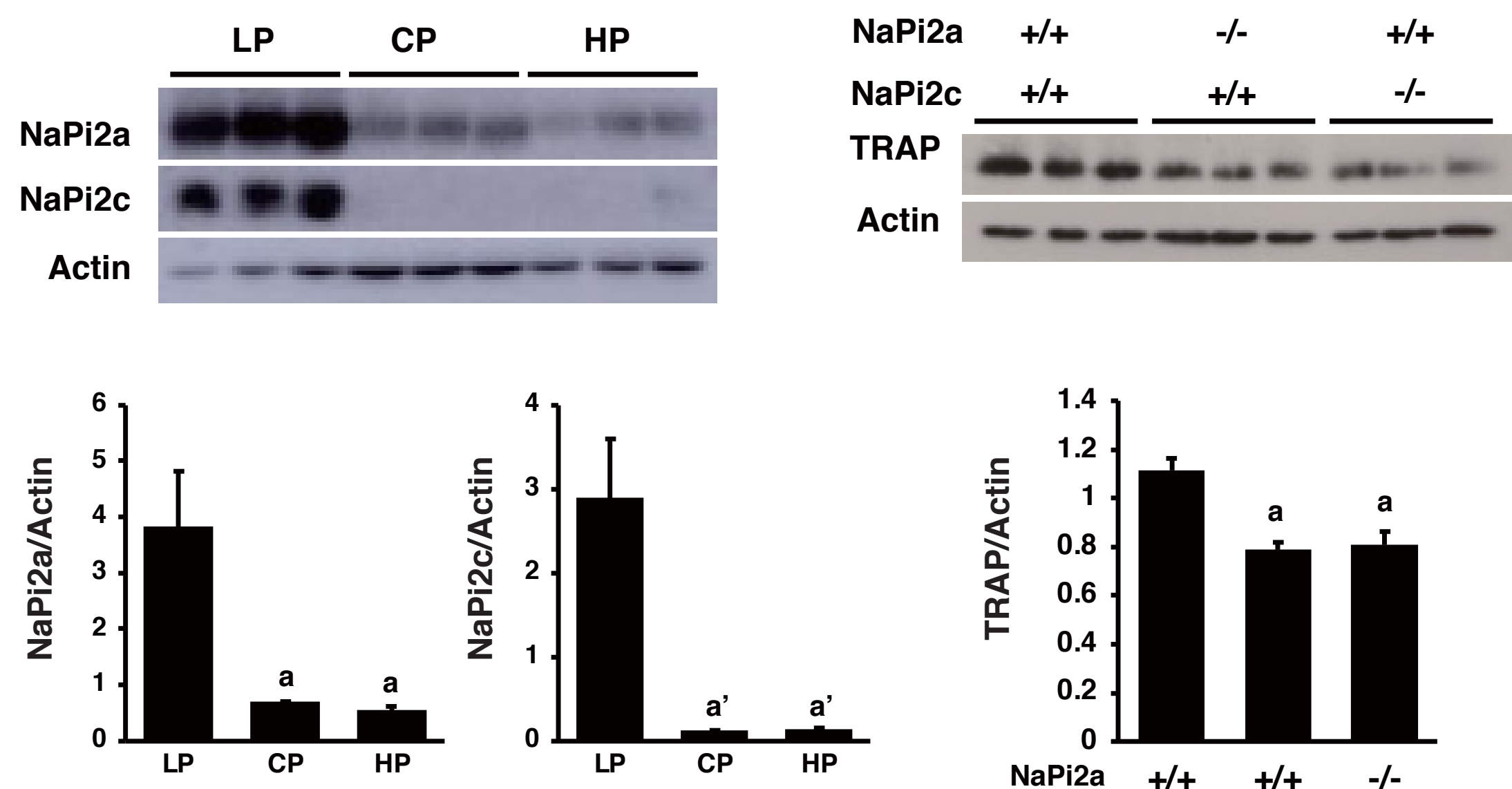

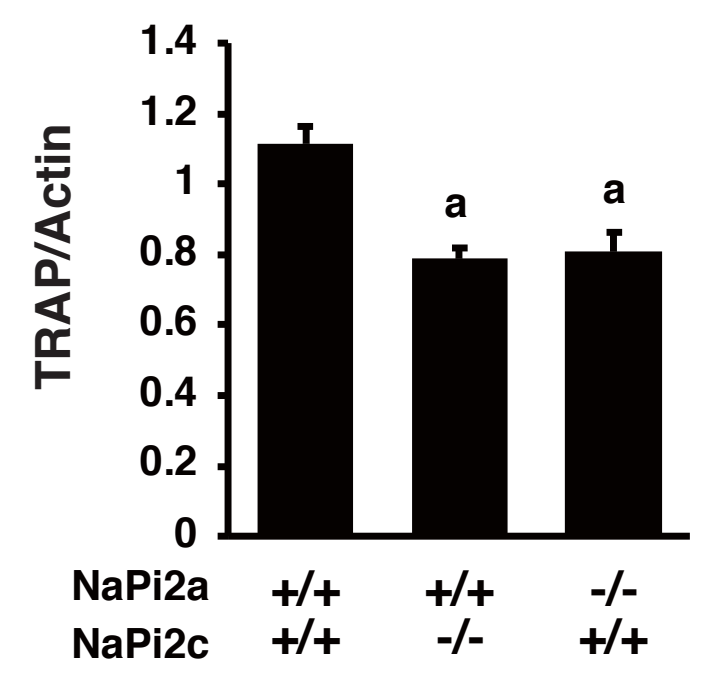


Figure 3
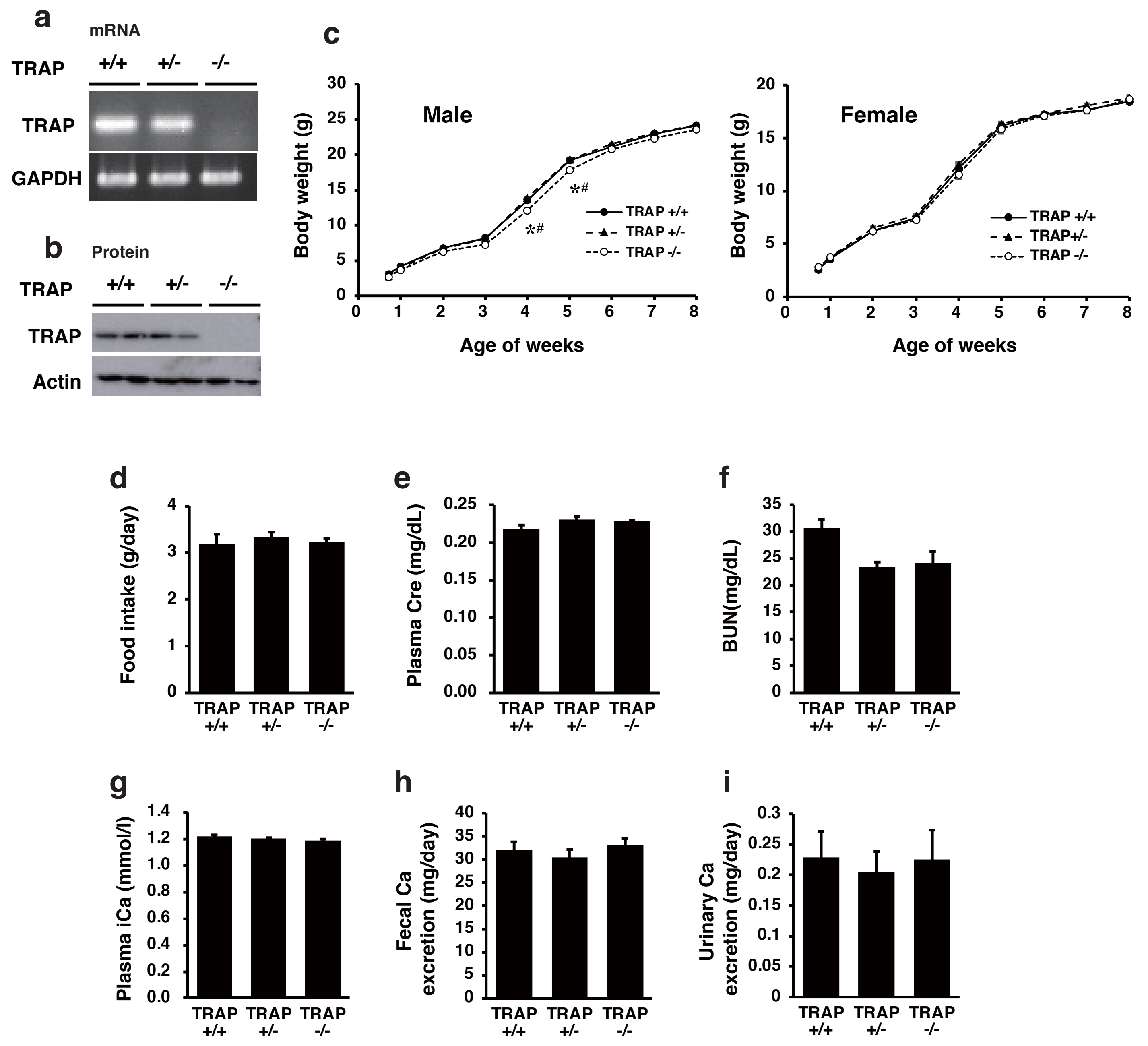

h
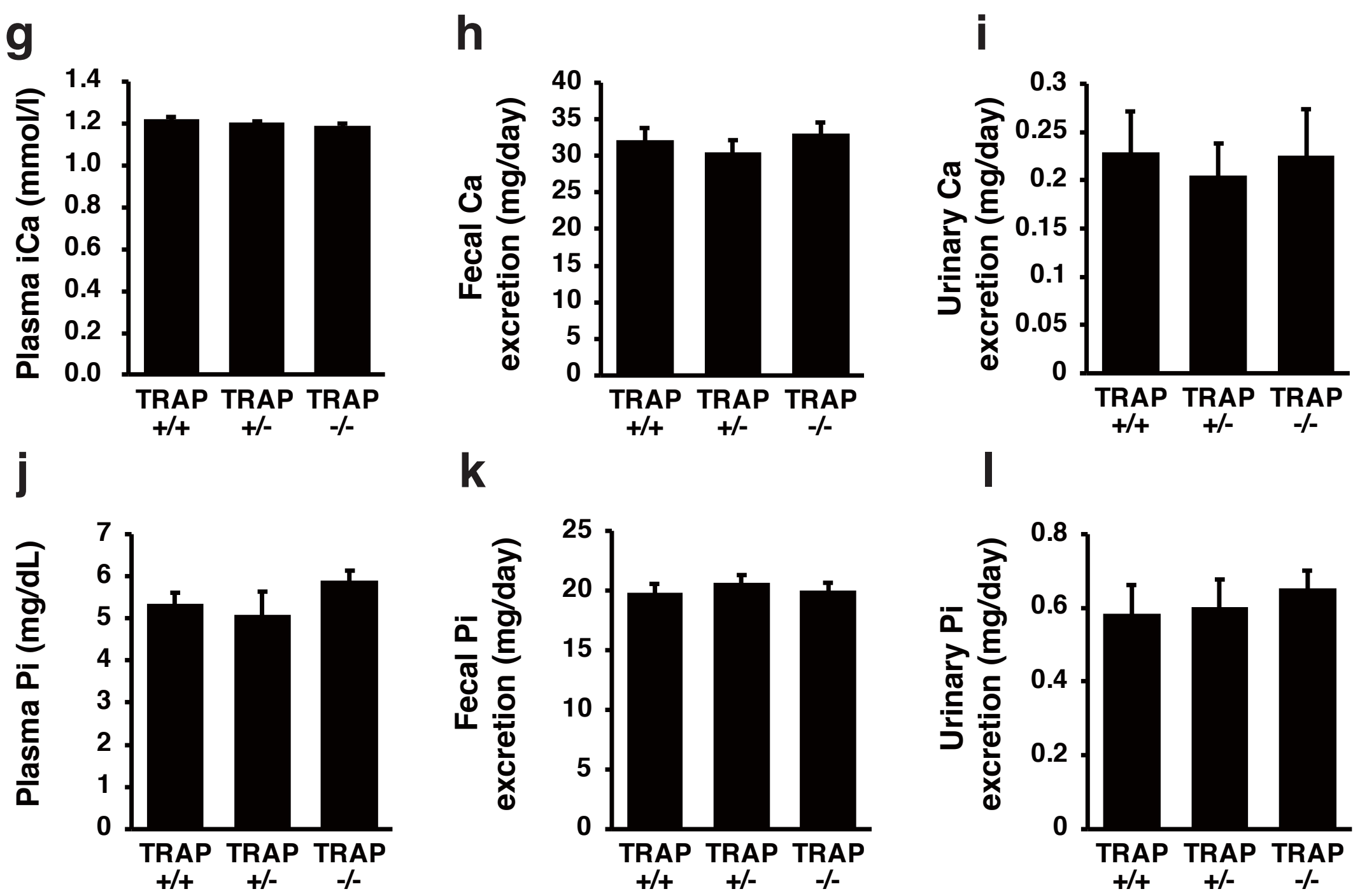

k
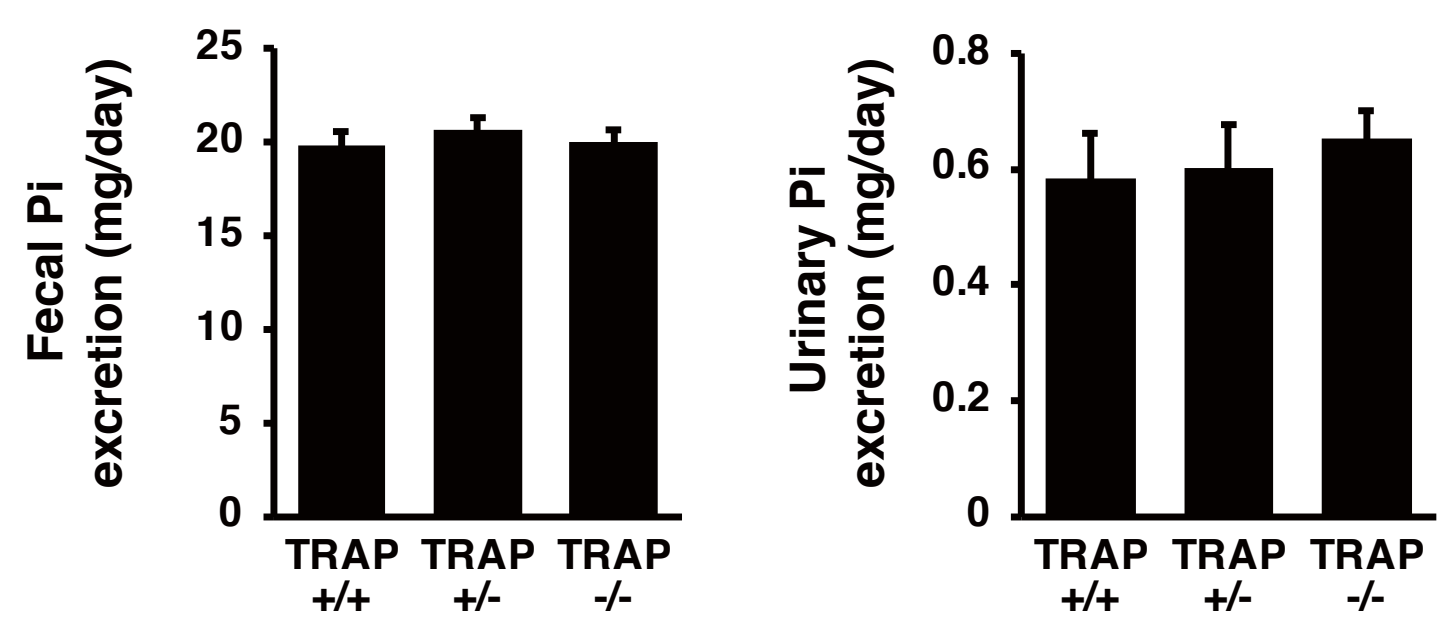
a

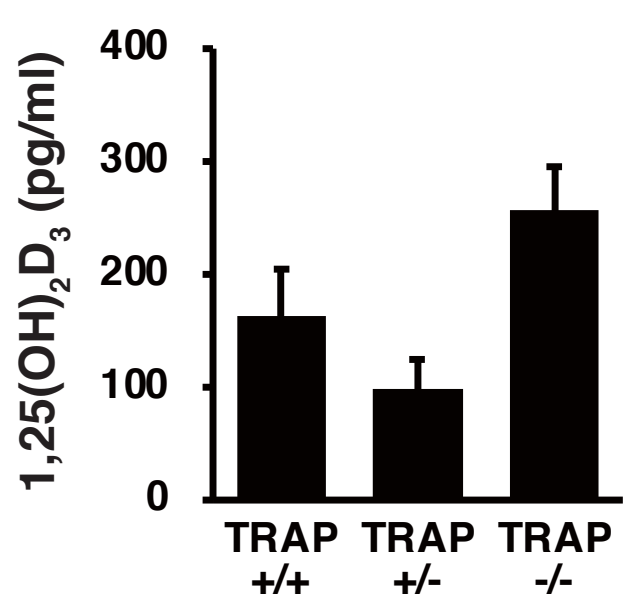

d

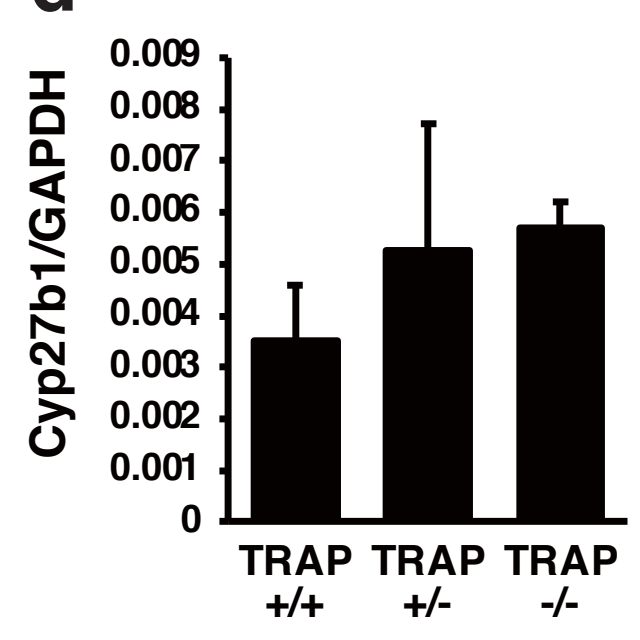

b

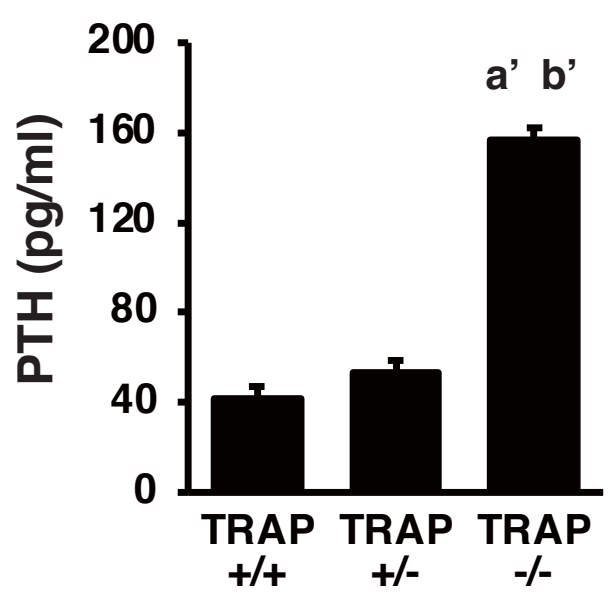

e

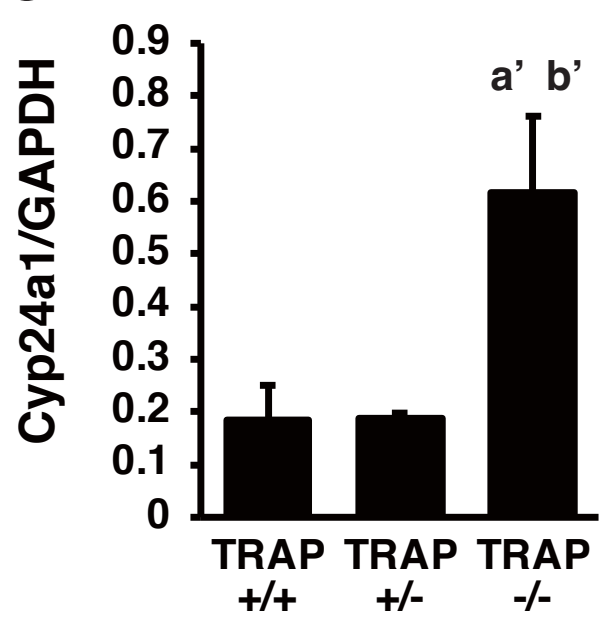

C

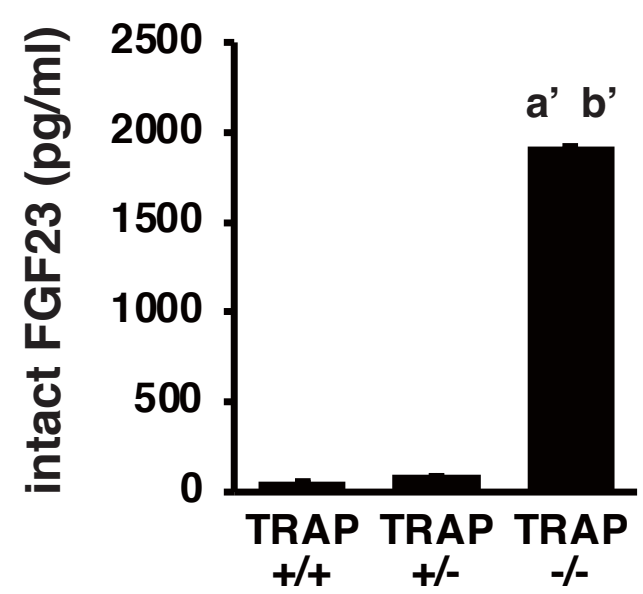

f

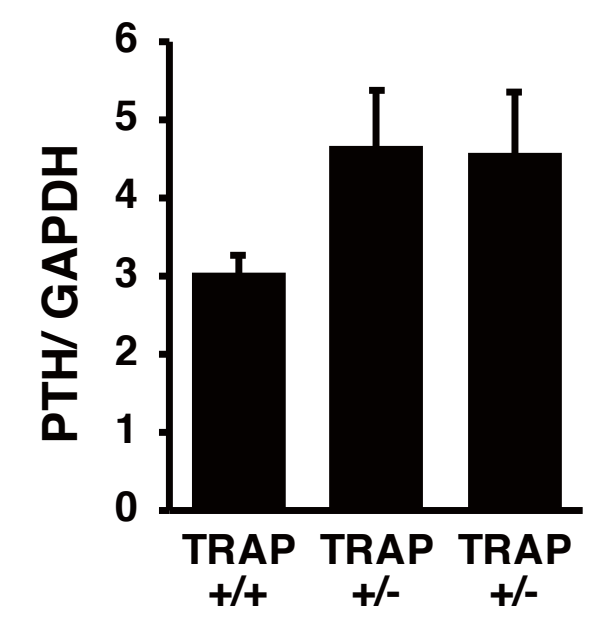

g

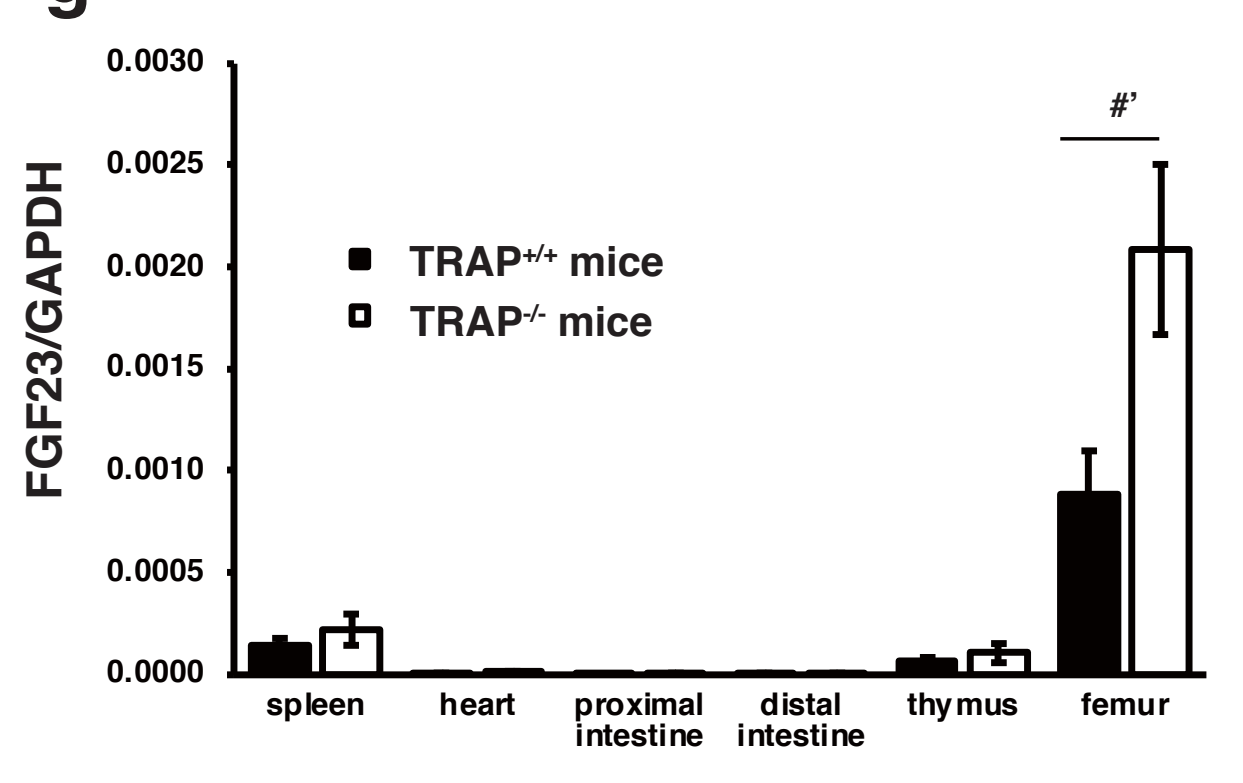

h

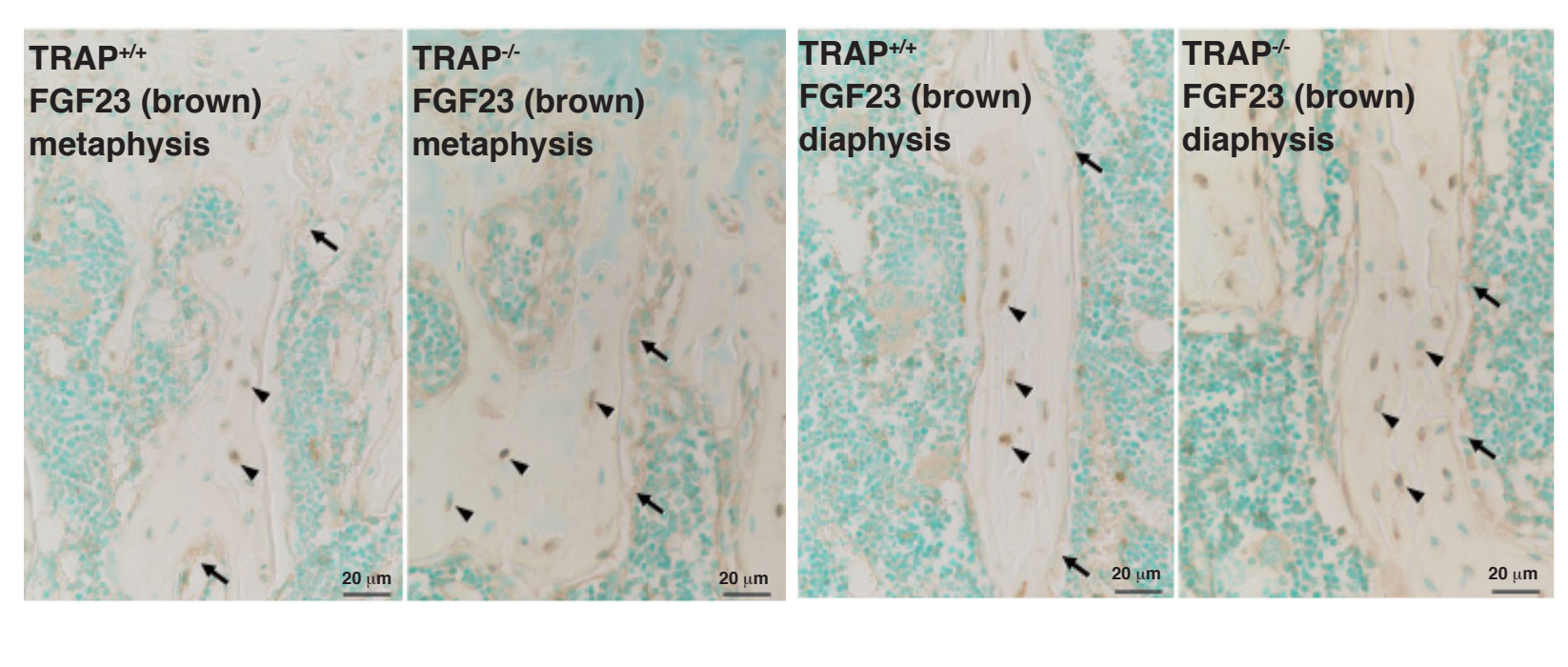


Figure 5

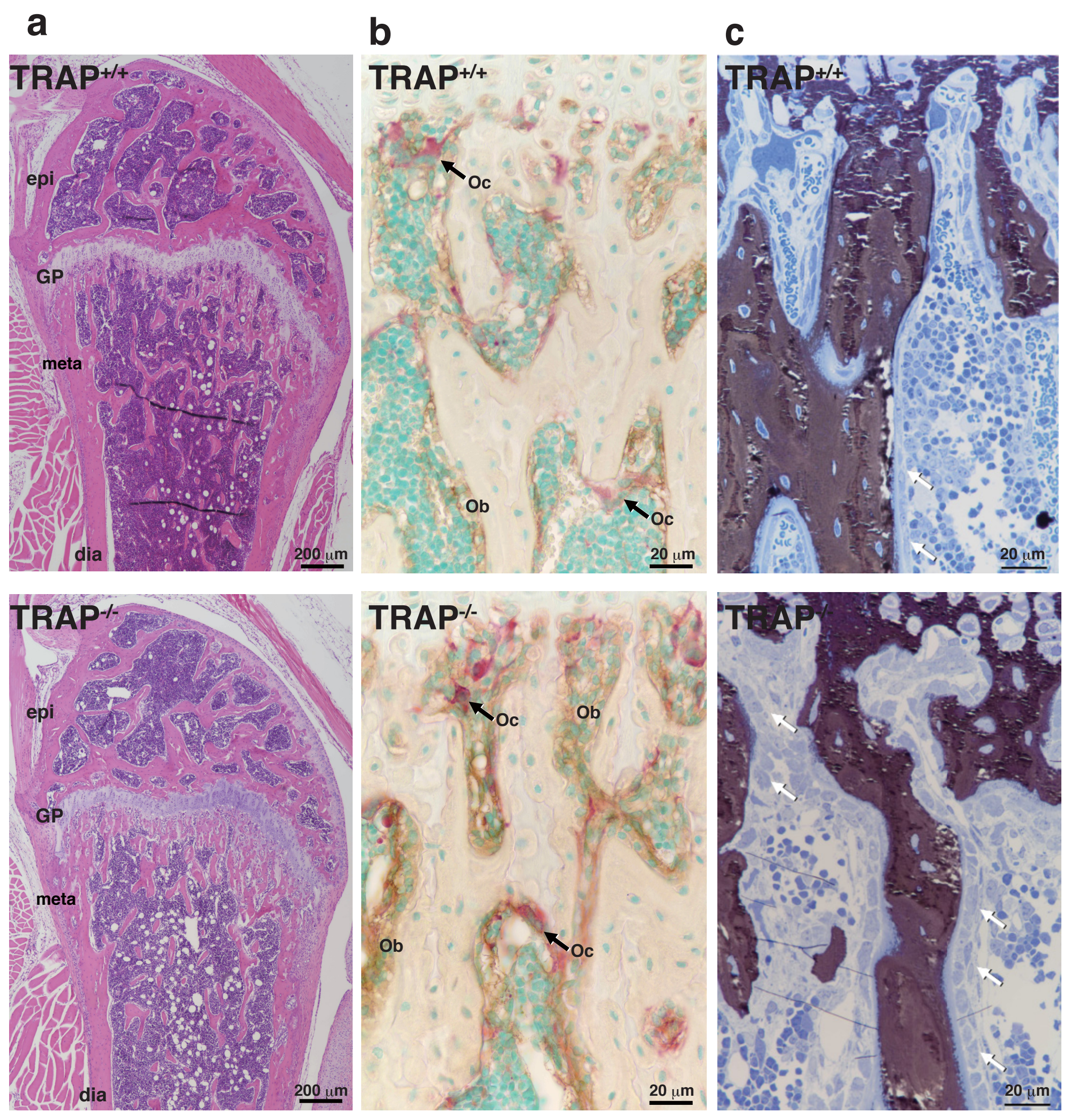




\section{Figure 6}
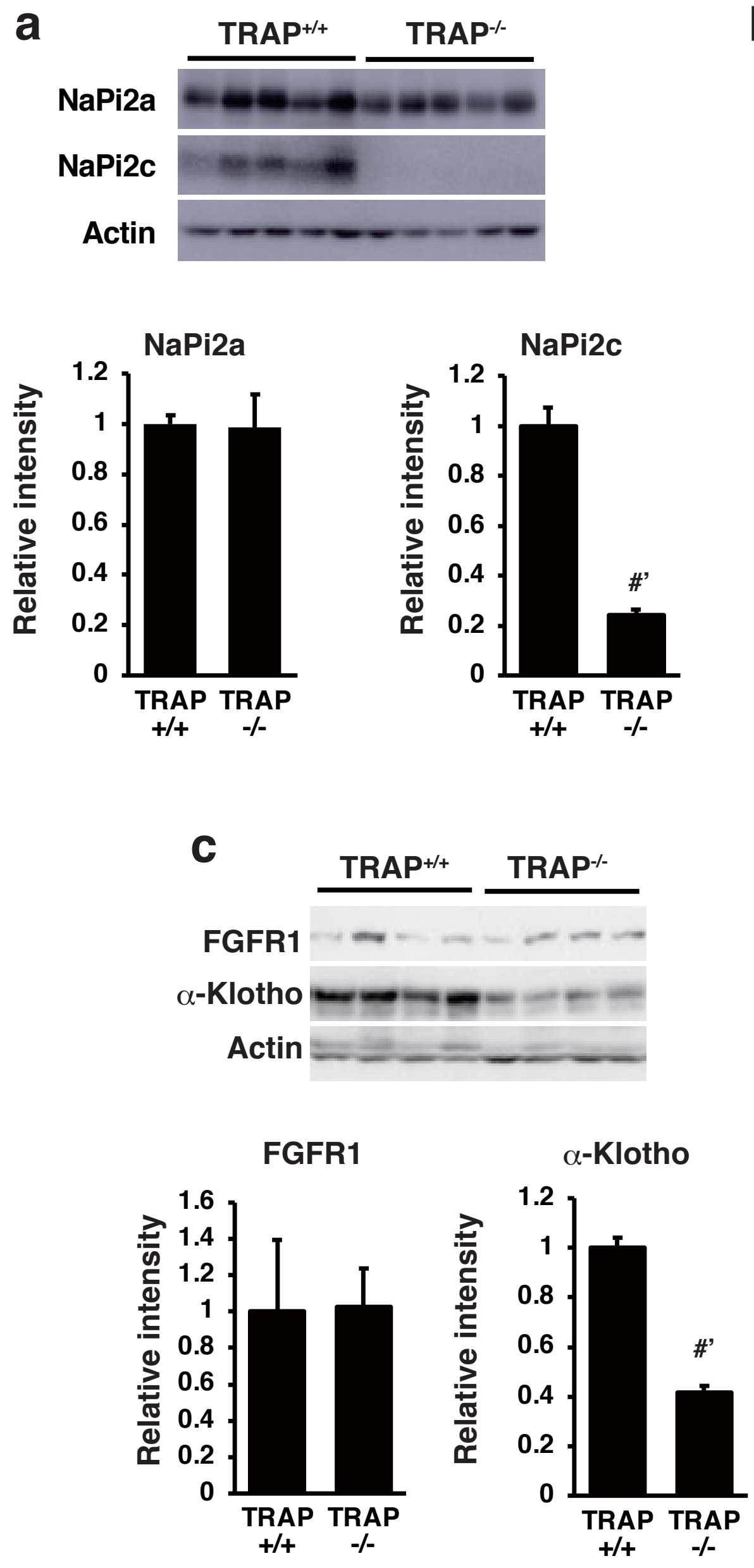
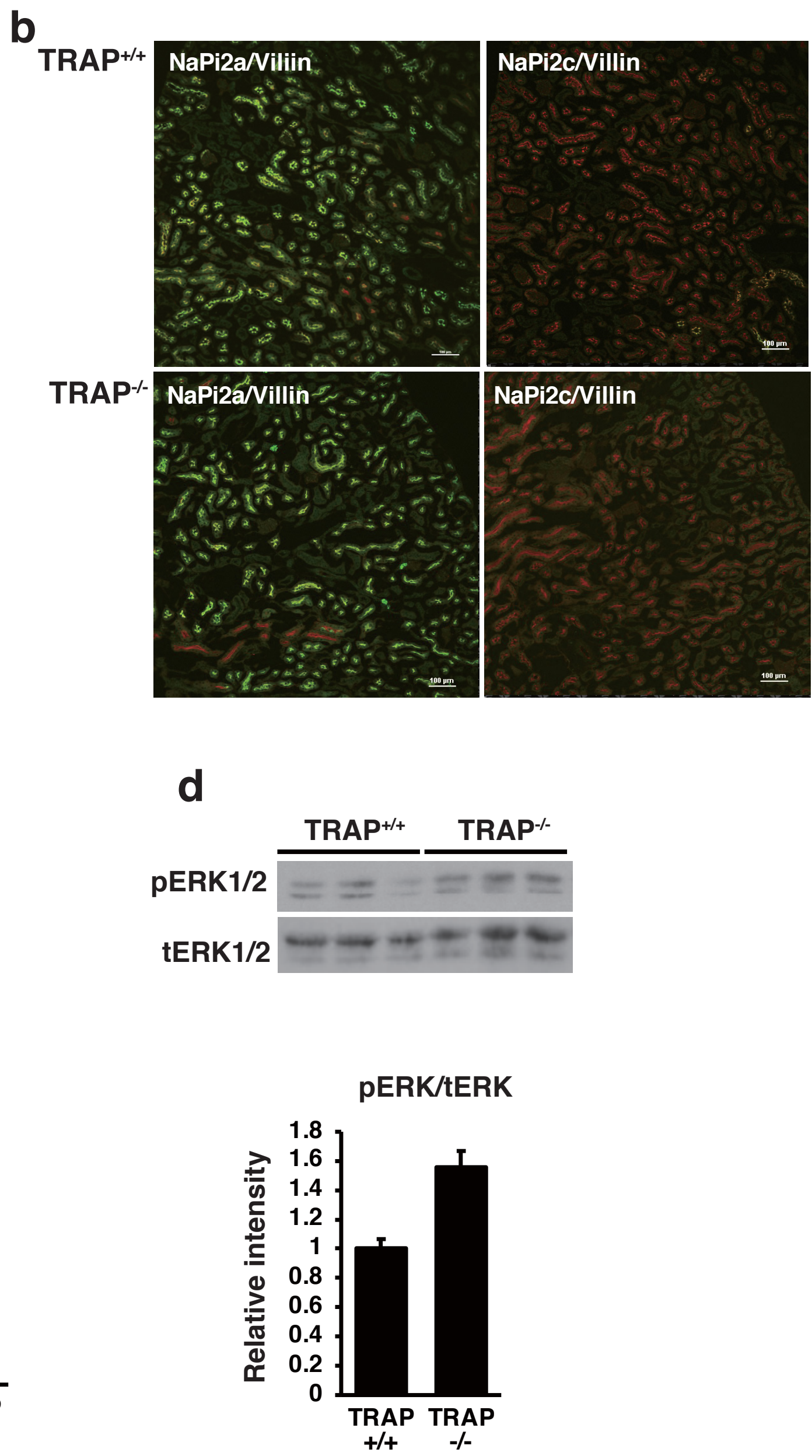


\section{Figure 7}

a
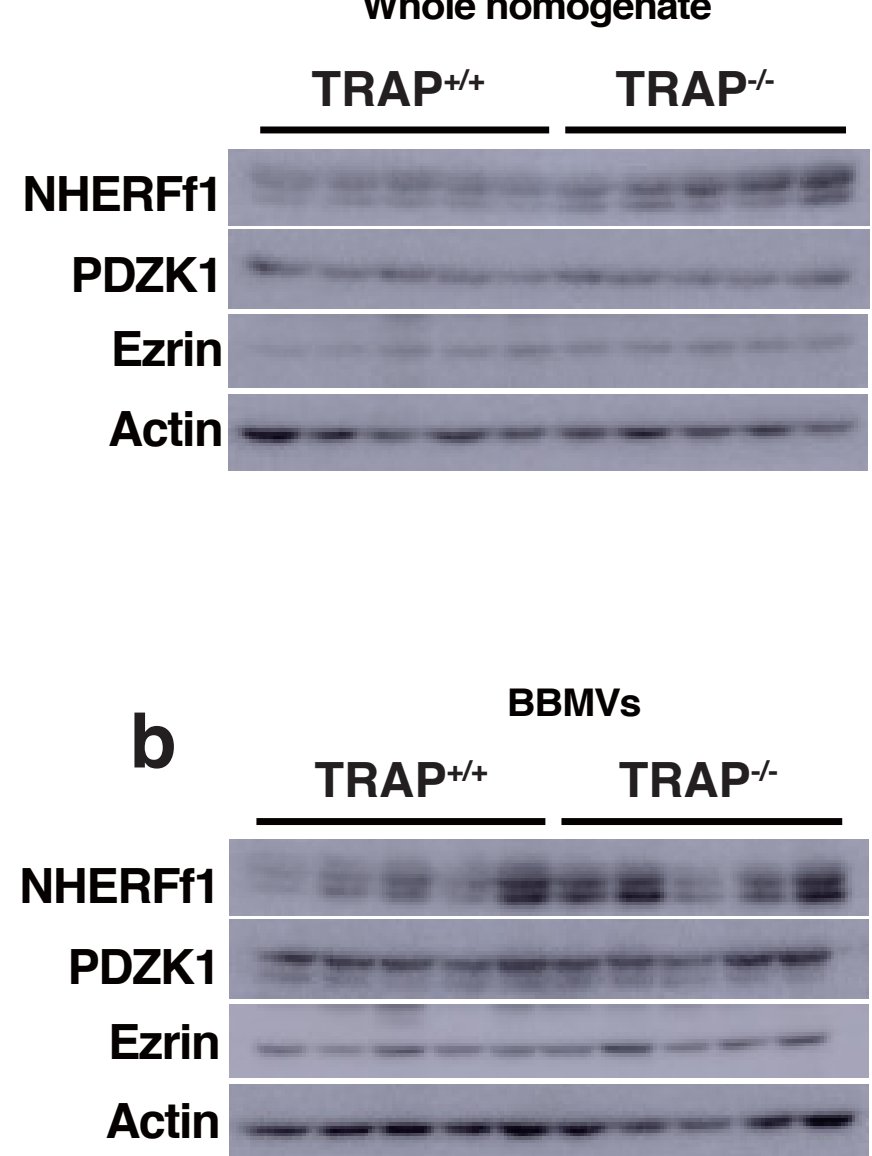
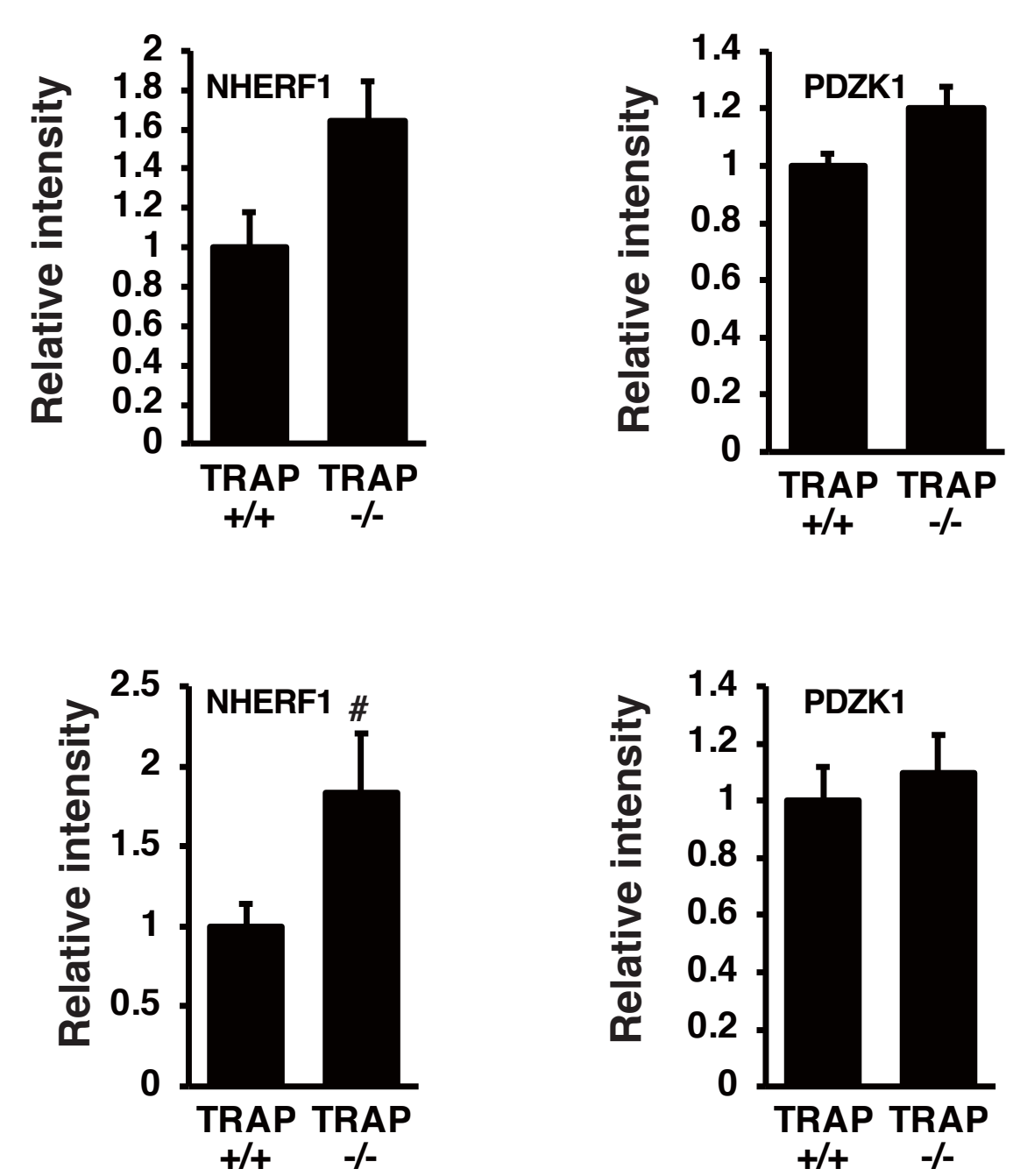

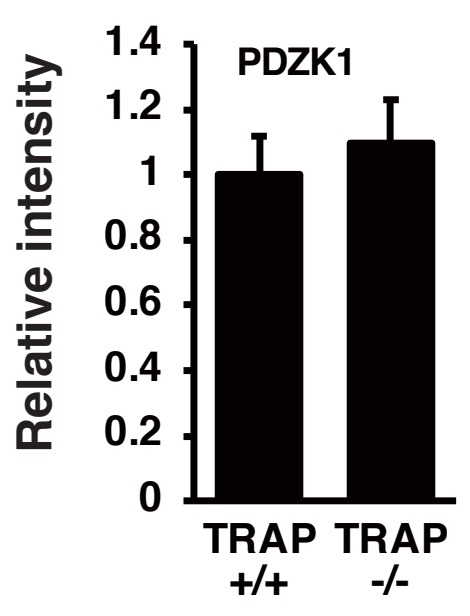

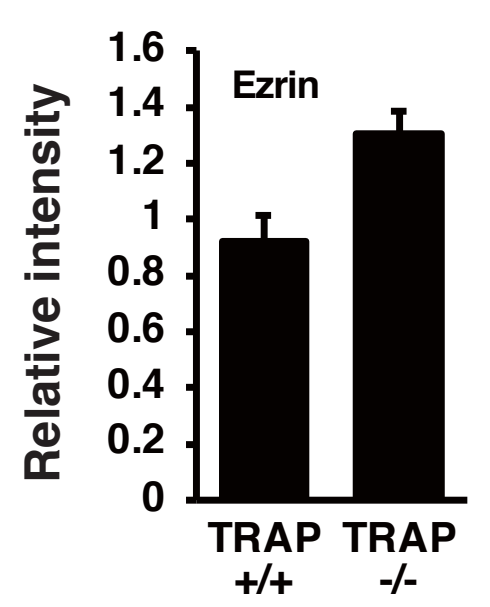

C WT TRAP $2 a$
KO KO

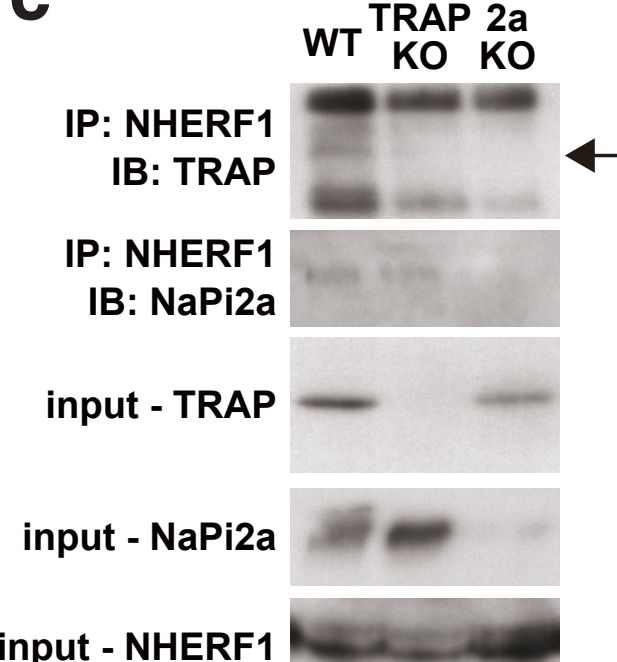

d

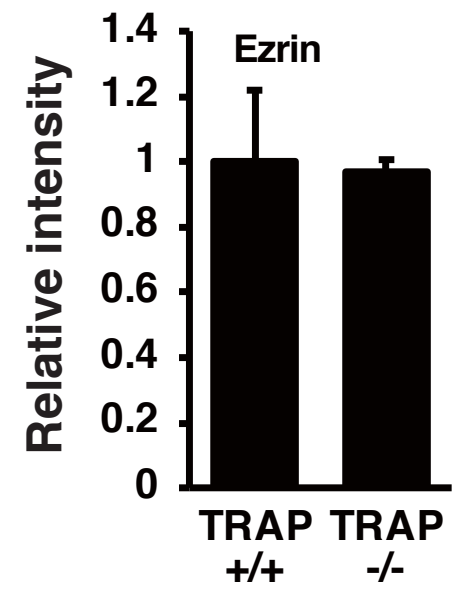

IP: TRAP WT TRAP
KO KO

IP: TRAP

IP: TRAP IB: NaPi2a

input - TRAP

input - NaPi2a 


\section{Figure 8}

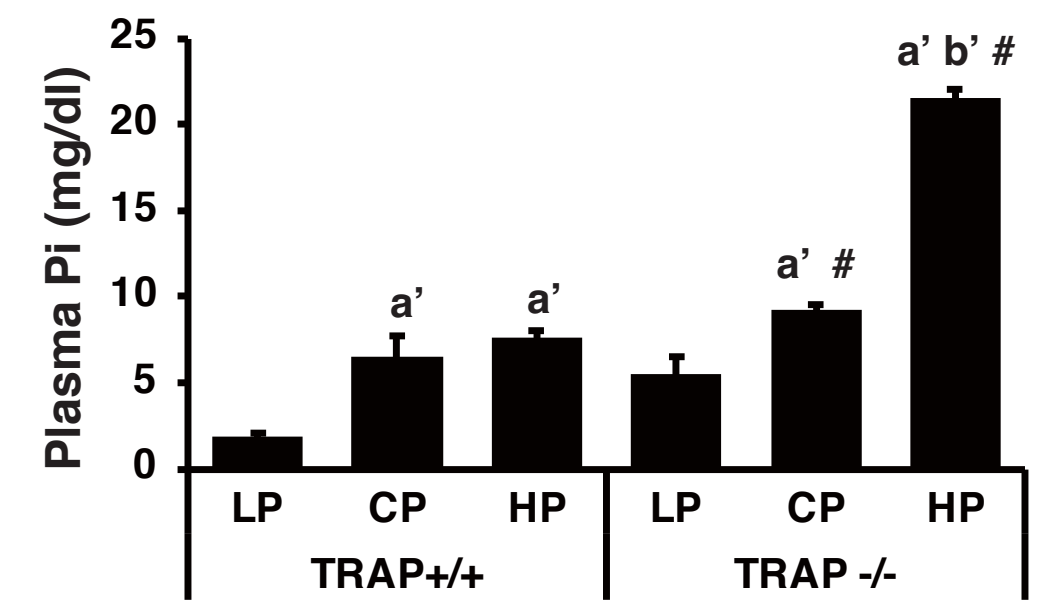

b

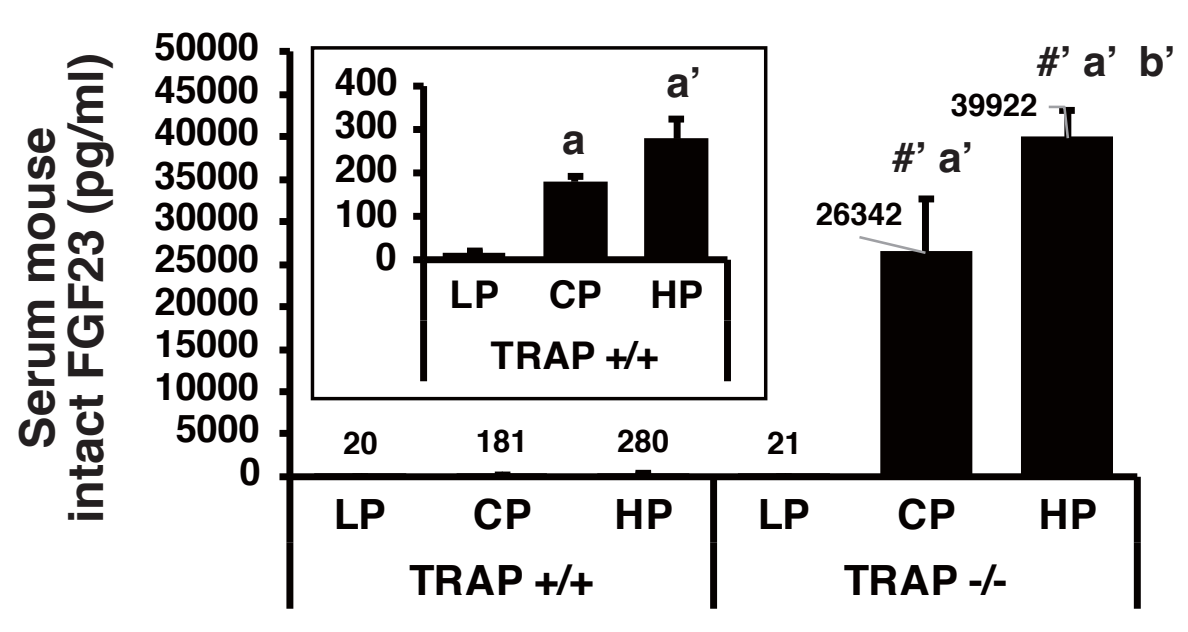

d

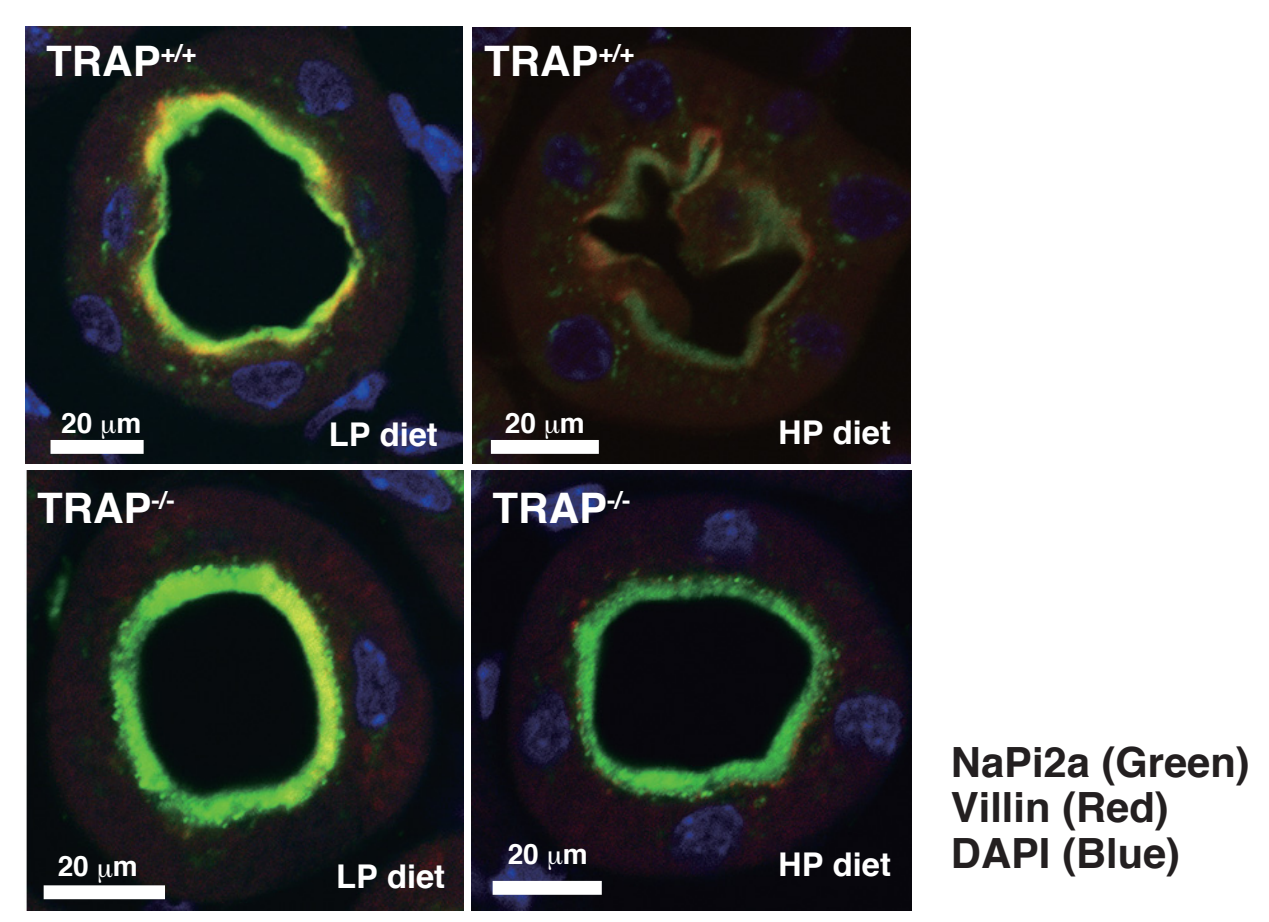

C
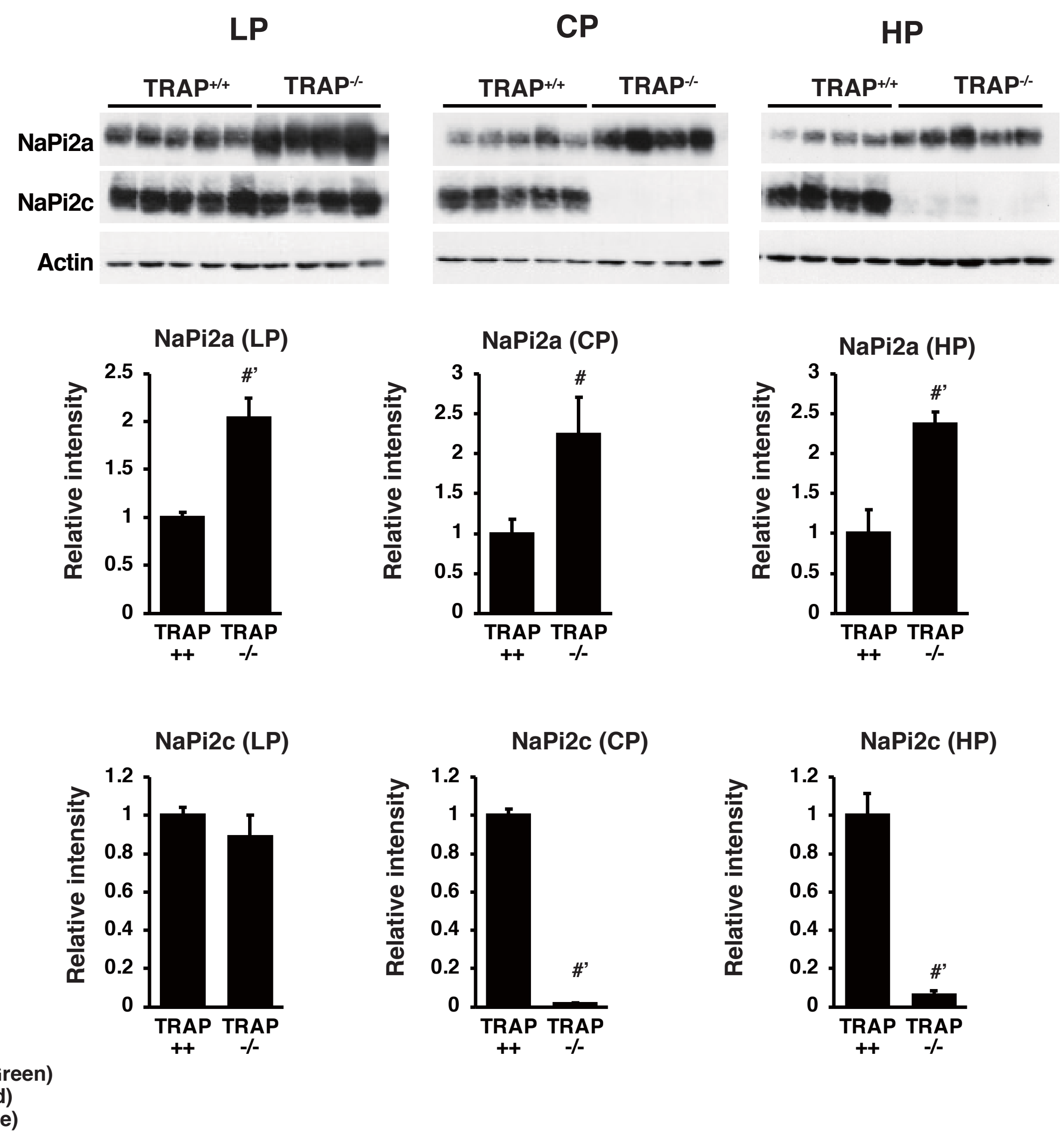
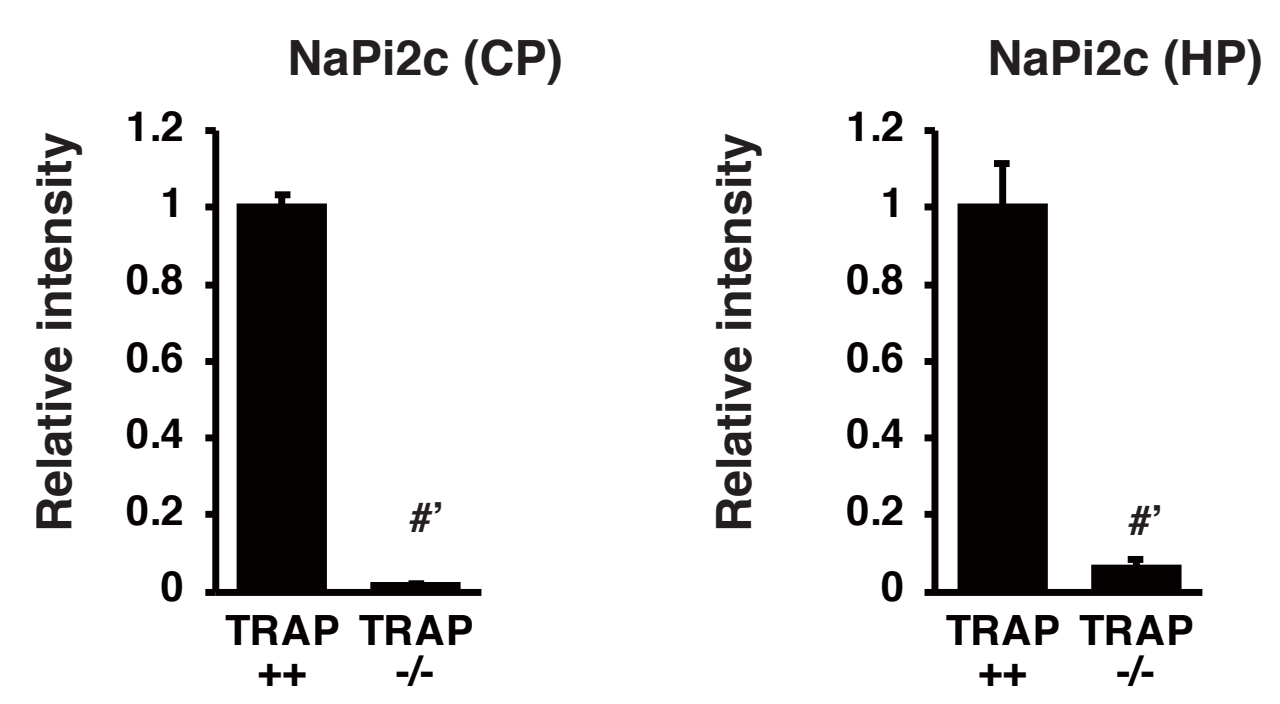
Figure 9

a

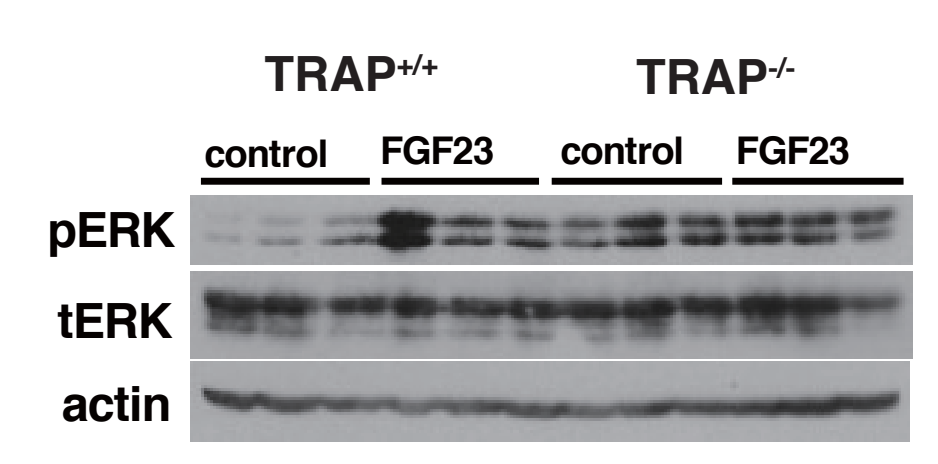

C

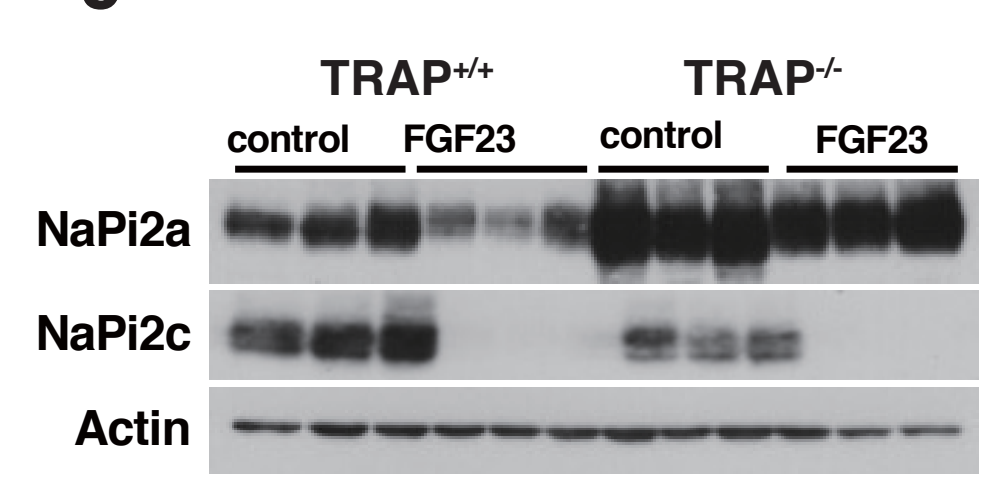

d

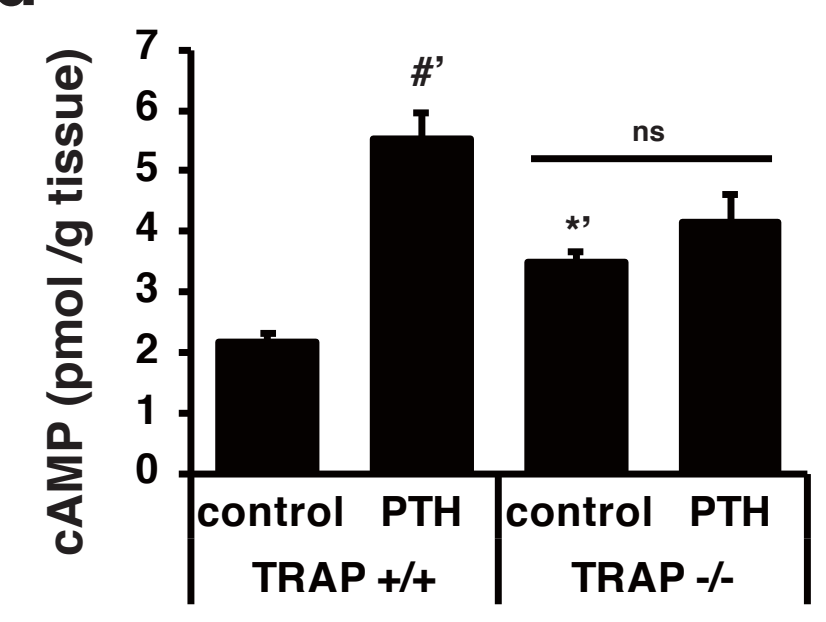

9
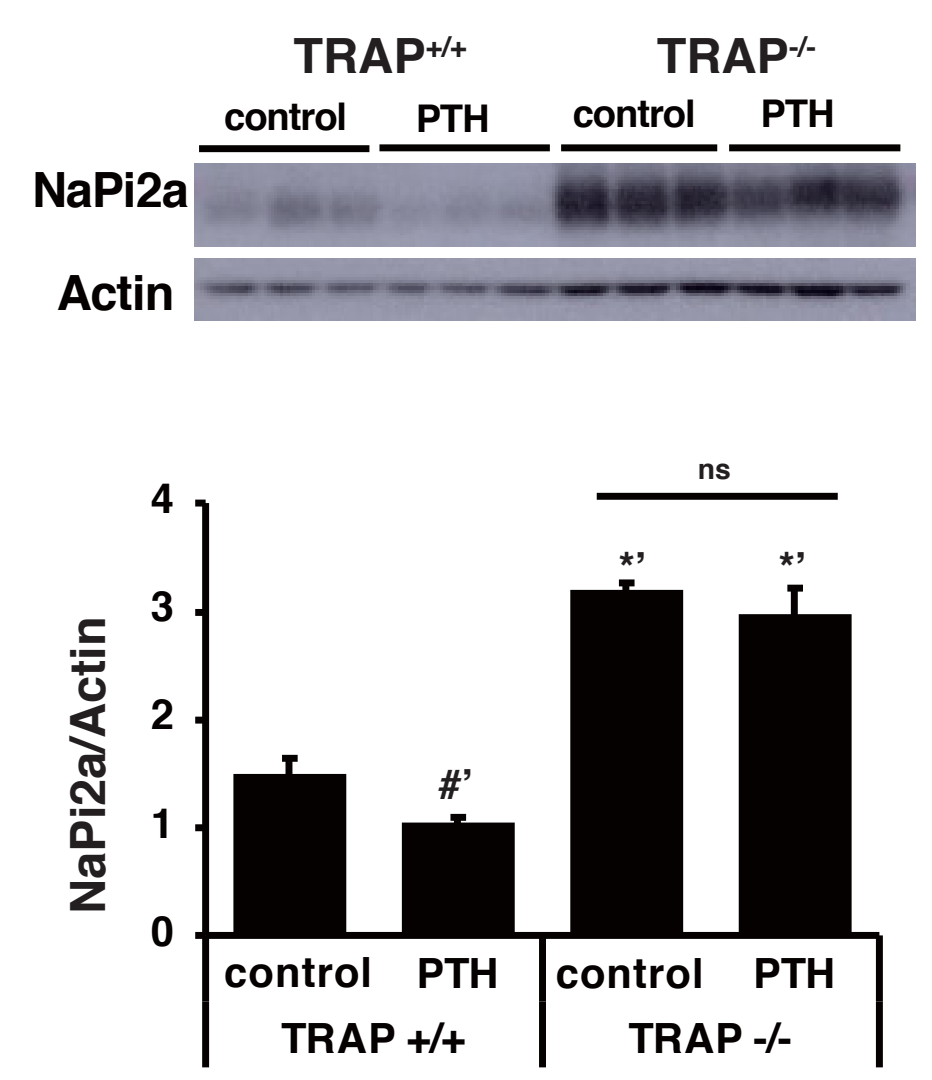

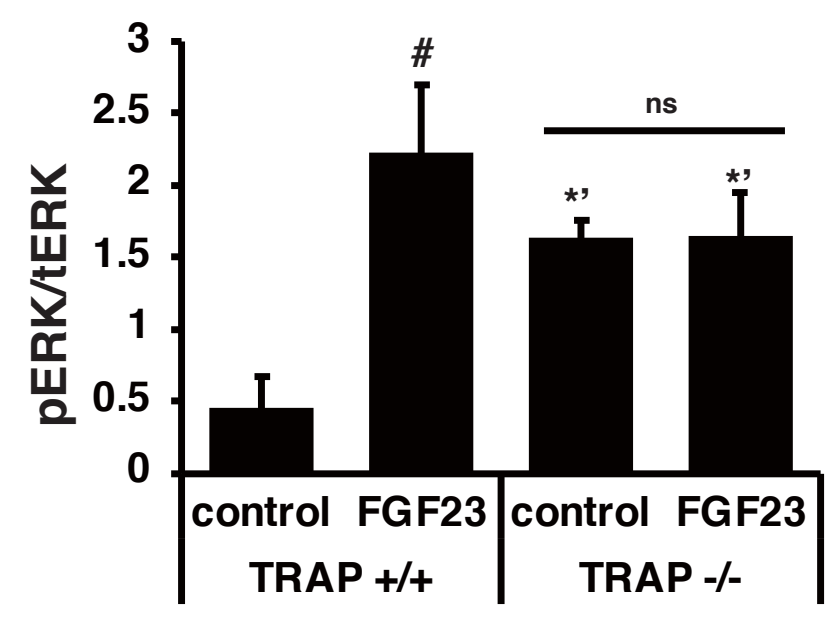

b
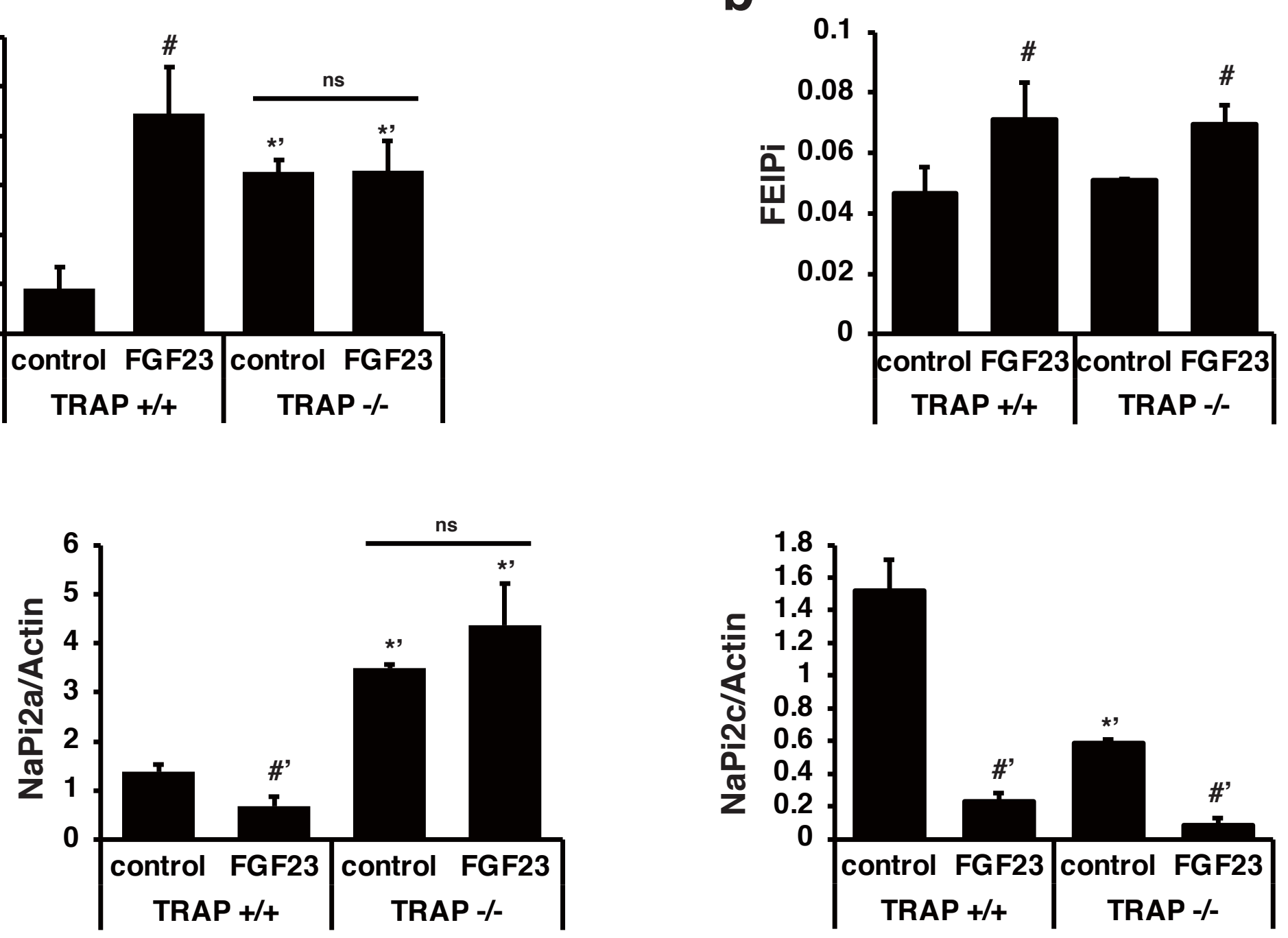

e
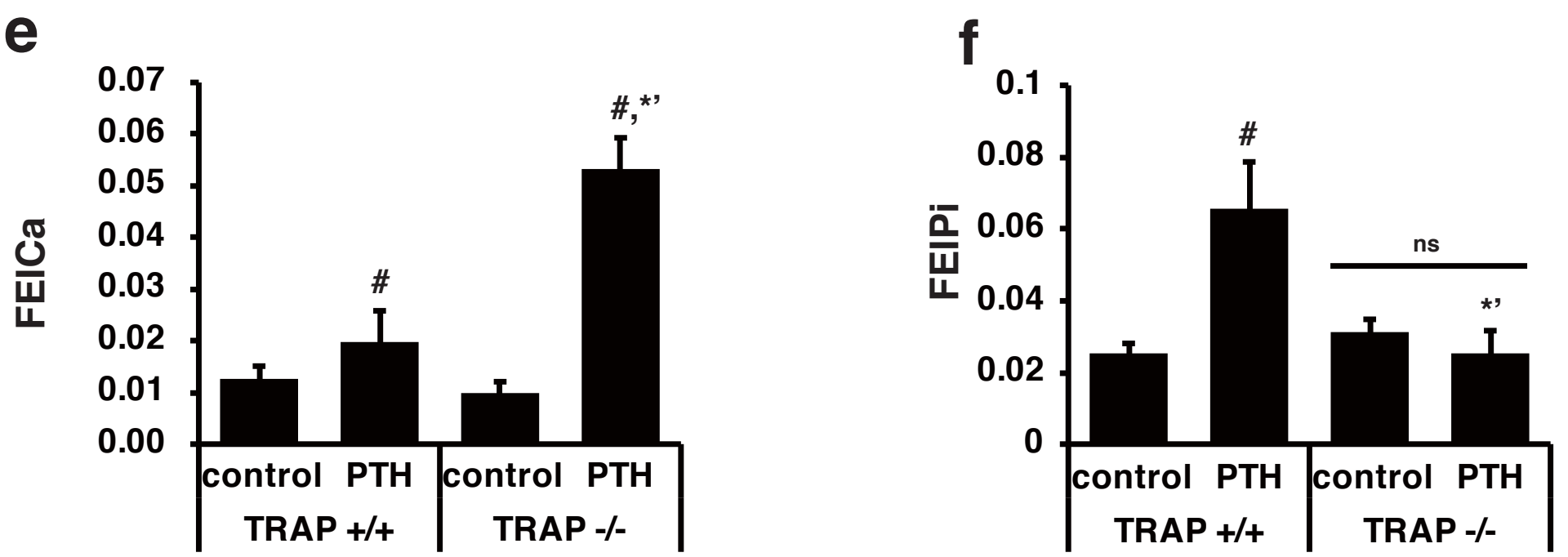

h

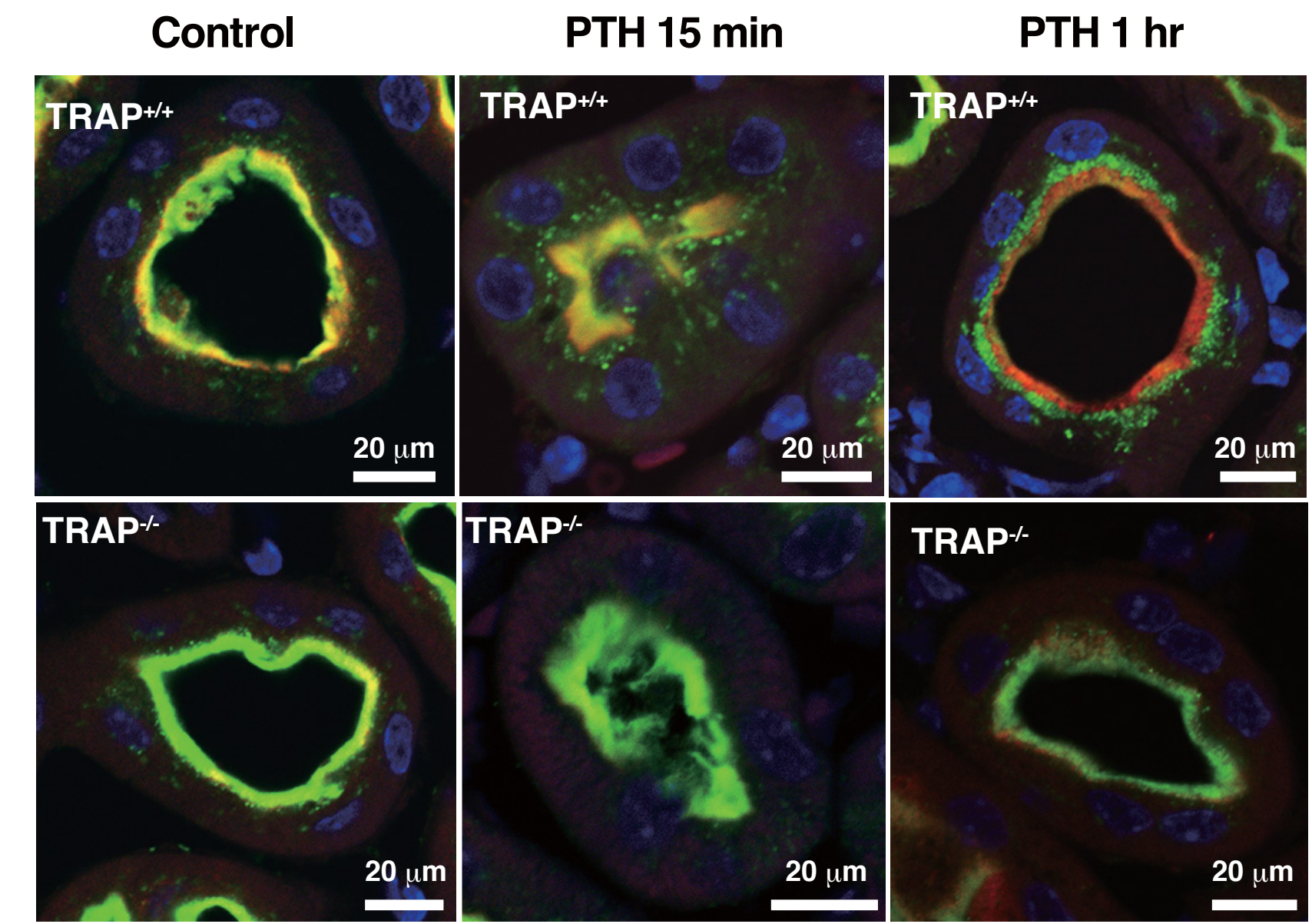

NaPi2a (Green)

Villin (Red)
DAPI (Blue) 


\section{Figure 10}

a

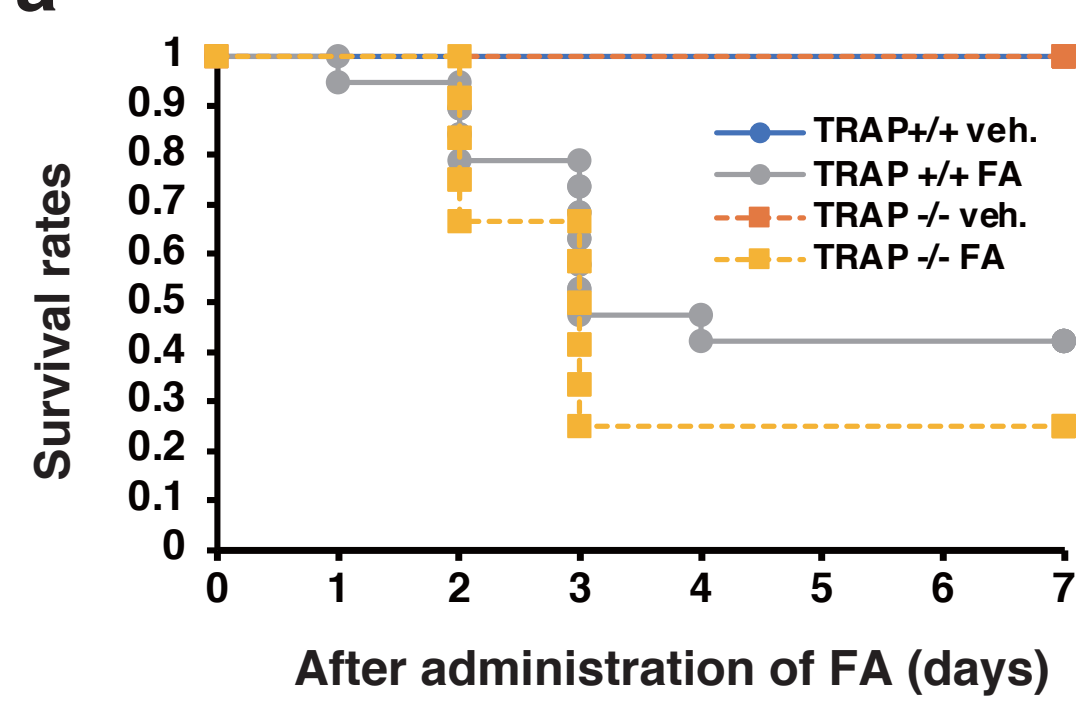

b

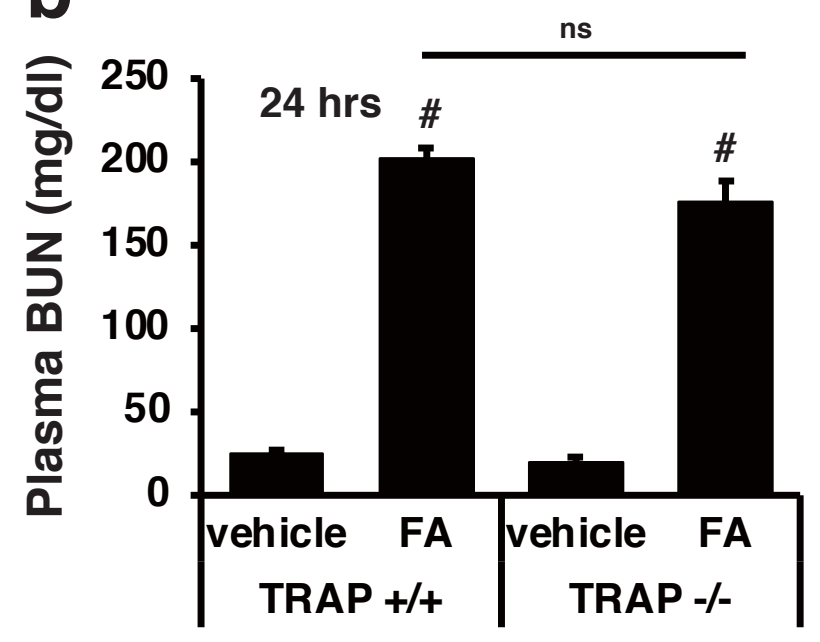

C

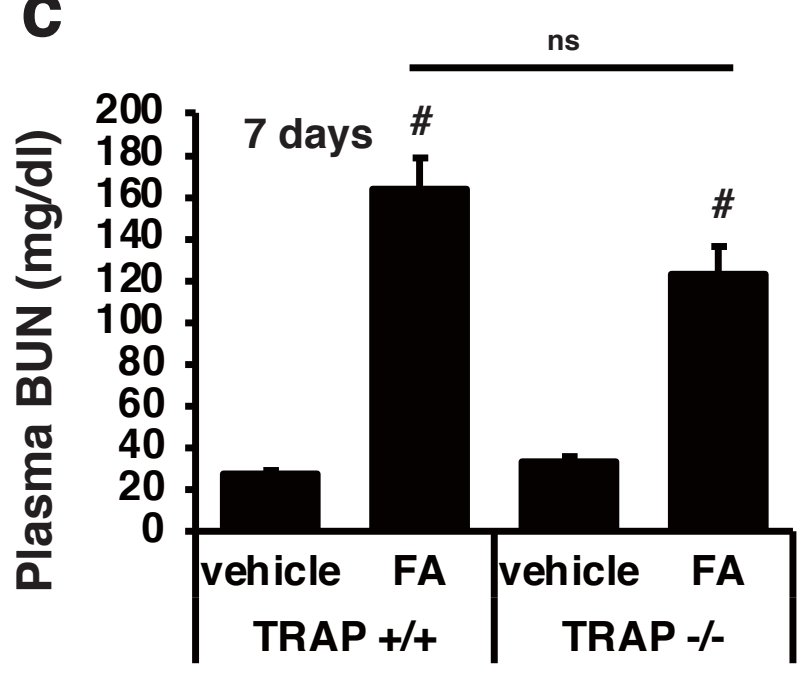

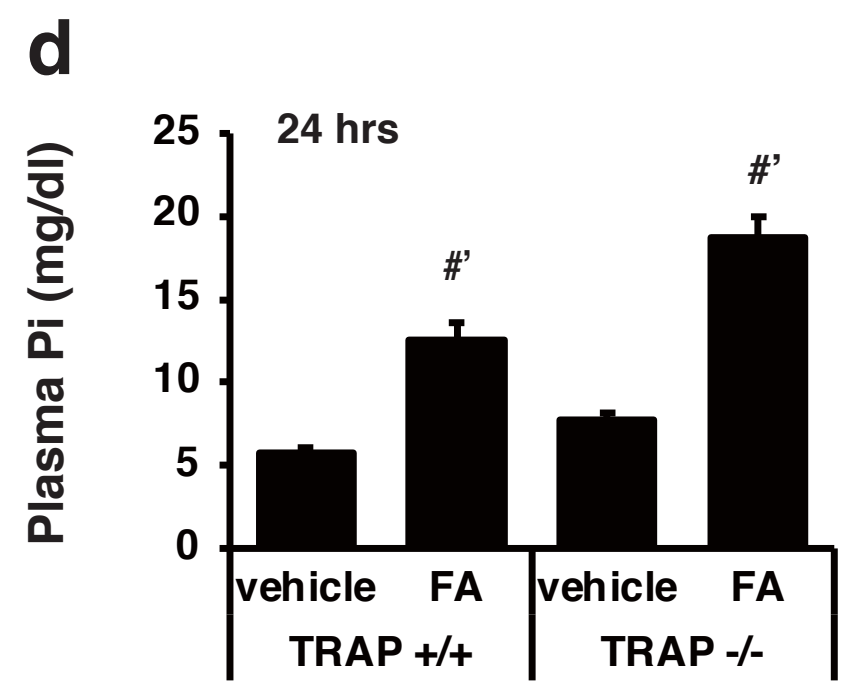

e

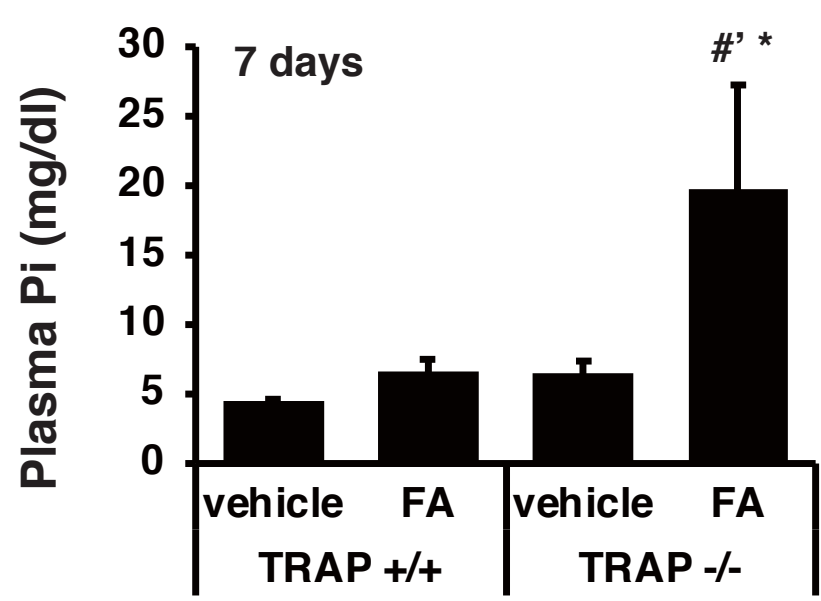

f

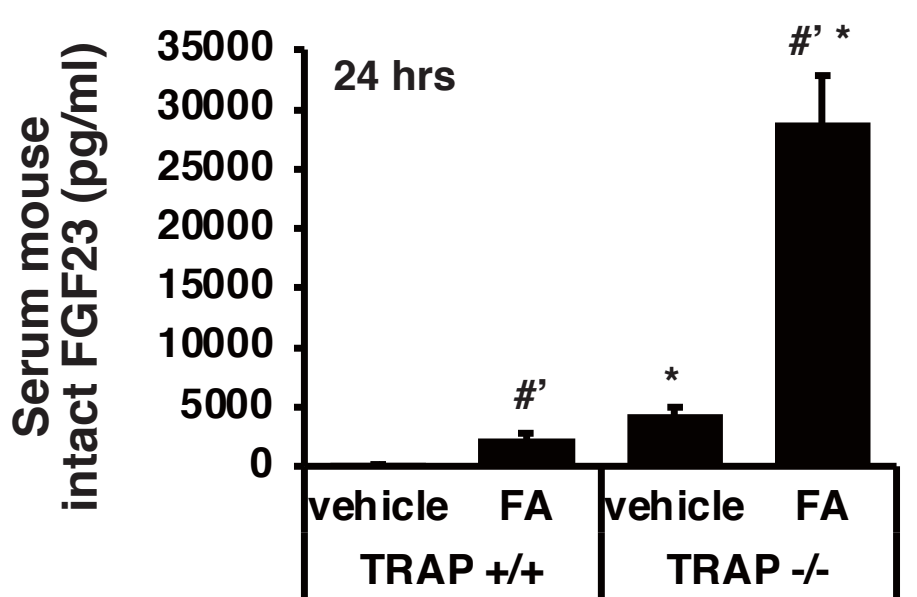

g

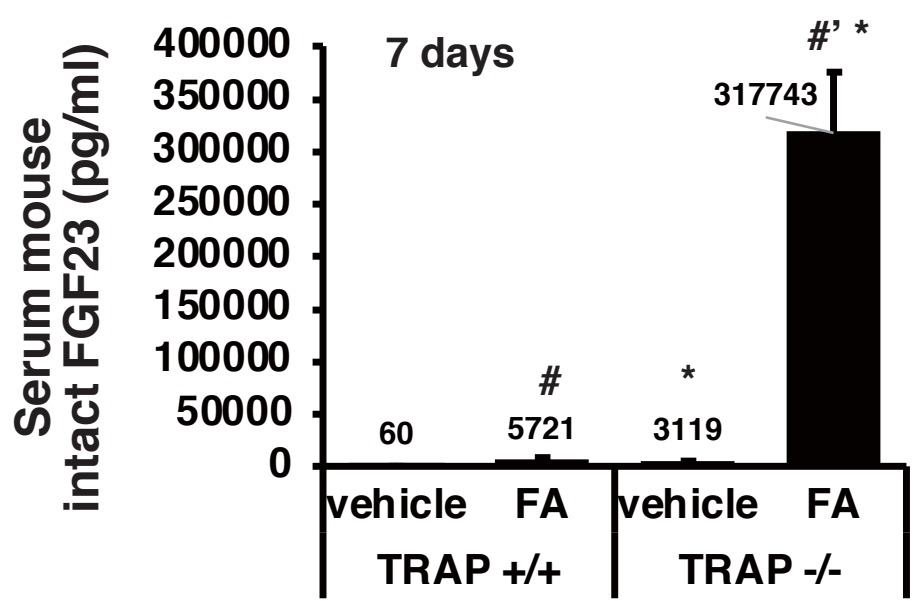

h

TRAP $^{+/+} \quad$ TRAP $^{-1-}$

vehicle $\mathrm{FA}$ vehicle FA

NaPi2a

$\mathrm{NaPi2c}$

Actin 
Figure 11

\section{WT mice}

High Pi

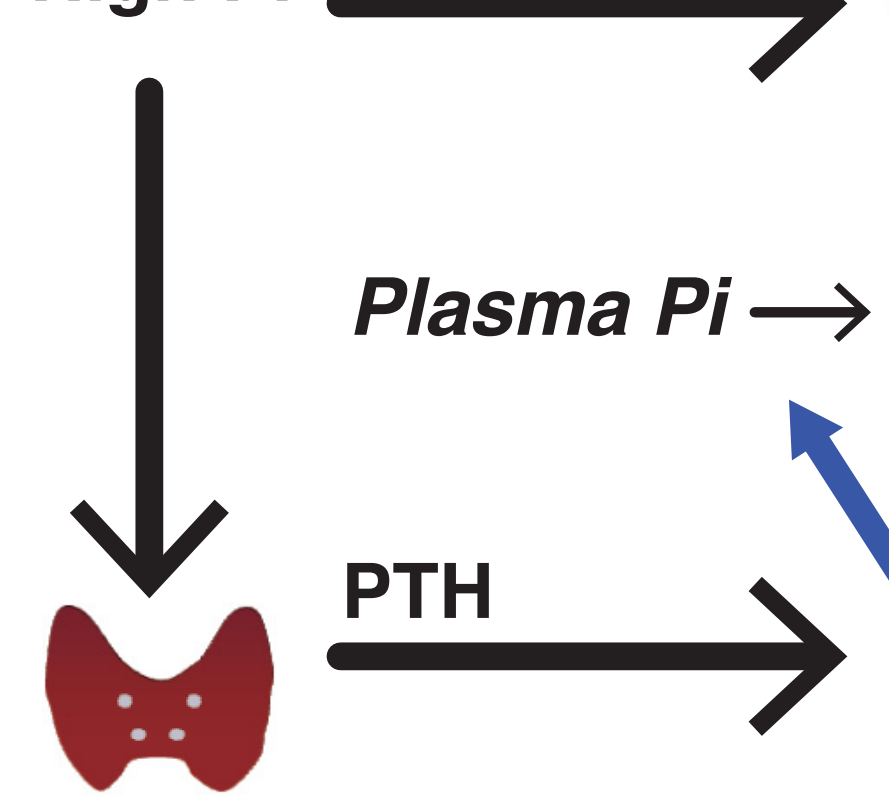

FGF23

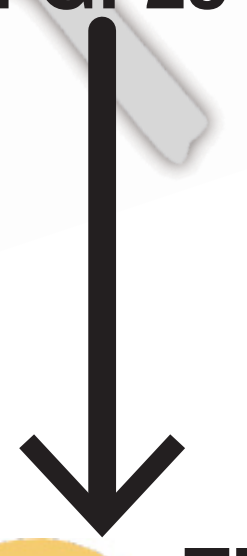

TRAP/NaPi2a-NHERF1 G
PT $\downarrow$ NaPi2a degradation Phosphaturia TRAP-KO mice

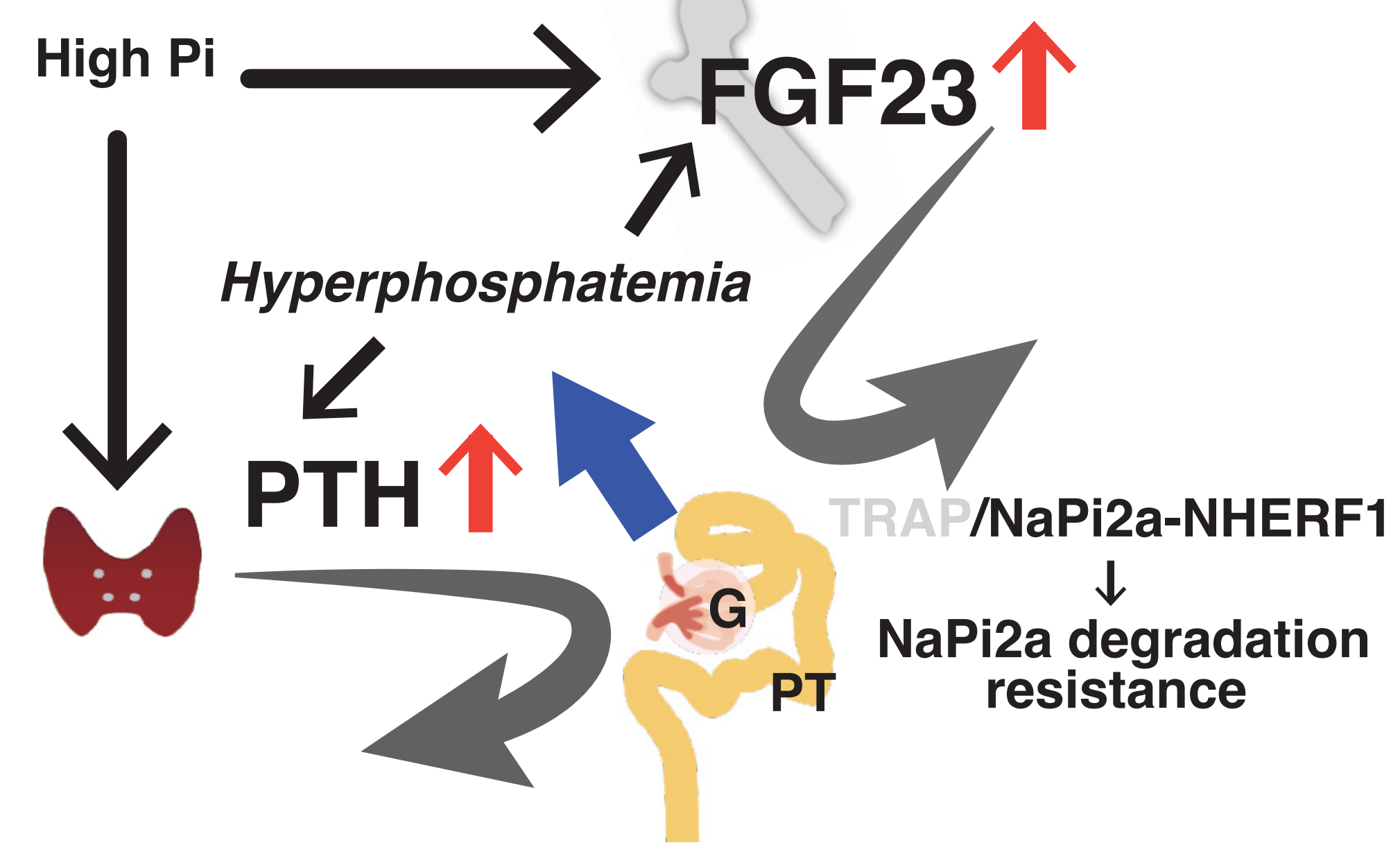




\section{Supplementary Files}

This is a list of supplementary files associated with this preprint. Click to download.

- 1242021SasakiSetal.Suptextfigurestables.pdf 